\title{
Echocardiographic Assessment of the Left Ventricular Physical Parameters: A Comparison Study in Patients With Significant and Non- Significant Coronary Artery Disease
}

\section{Zeinab Alsadat Ahmadi}

Tarbiat Modares University Faculty of Medical Sciences

Manijhe Mokhtari-Dizaji ( $\sim$ mokhtarm@modares.ac.ir)

Tarbiat Modares University https://orcid.org/0000-0003-1598-2038

Anita Sadeghpour

Iran University of Medical Sciences and Health Services: Tehran University of Medical Sciences

Hamideh Khesali

IUMS: Iran University of Medical Sciences

Ata Firouzi

Iran University of Medical Sciences and Health Services: Tehran University of Medical Sciences

\section{Research}

Keywords: Coronary artery disease, Speckle tracking echocardiography, Wall stress, Strain

Posted Date: November 12th, 2020

DOI: https://doi.org/10.21203/rs.3.rs-104043/v1

License: (c) (i) This work is licensed under a Creative Commons Attribution 4.0 International License.

Read Full License 


\section{Abstract}

\section{Background}

In this study, physical parameters of the strain of left ventricle (LV), wall stress with a thick-walled ellipsoidal model, and elastic modulus of LV were extracted for distinguishing patients who were stent candidates.

Materials and Methods

Eighty-eight patients with suspected coronary artery disease (CAD) underwent echocardiography and angiography. Based on angiography results, the patients were divided into two groups (64 patients candidate for $\mathrm{PCl}$ (percutaneous coronary intervention) and 24 cases in the control group). Long-axis and short-axis echocardiographic views were acquired. Radial, longitudinal, and circumferential stress were estimated by the thick-walled ellipsoidal model. Circumferential strain (CS) and longitudinal strain (Ls) were obtained for 18 segments in the endocardium layer of LV, and then GLS (global longitudinal strain) and GCS (global circumferential strain) were calculated.

Result

Anterior and inferoseptal circumferential wall stresses in end-systole (ES) were statistically significant $(P<0.05)$, but radial and longitudinal stress were not significant $(P>0.05)$. Peak systolic GCS and GLS were lower in the $\mathrm{PCl}$ group $(-18.13 \pm 3.03$ and $-16.57 \pm 2.88 \%)$ compared to the control group $(-21.97 \pm 3.97$ and $19.14 \pm 2.17 \%)$, respectively $(p<0.05)$. The receiver operator characteristic curve $(\mathrm{ROC})$ analysis revealed that GLS and GCS had the highest area under the ROC curve with a sensitivity of $83 \%$ and specificity of $63 \%$ for GLS and sensitivity of $71 \%$ and specificity of $59 \%$ for GCS.

\section{Conclusion}

Stress and strain parameters are suggested as non-invasive and quantitative tools for measuring left ventricular function before angiography. Regional elastic modulus was a powerful predictor that can be distinguishing significant CAD patients.

\section{Introduction}

Coronary artery disease (CAD) is the most common type of heart disease. In CAD, the blood vessels that supply the heart muscle become harder and narrower. Thus, less blood flows into the arteries, the heart muscle cannot receive the blood or oxygen it needs, sudden blockage in the blood supply occurs. Over time, in addition to changes in vascular function, thickening of the membrane of the myocardial arteries prevents left ventricular perfusion, attenuates the heart muscle, and leads to heart failure and arrhythmia [1]. The only gold standard diagnostic method for detecting coronary artery stenosis is coronary angiography (CAG). Limitations of CAG include hospitalization, risk of ionizing radiation, invasive interventions, being time-consuming, and high costs. Furthermore, most patients do not have significant 
stenosis and are not a candidate for revascularization therapy, so CAG is not necessary for all patients. Due to the mentioned limitations and the increased workload in the angiography department, providing a non-invasive method by evaluating the physical and mechanical parameters of the myocardium can be useful for the diagnostic of CAD patients [2,3]. Despite impaired left ventricular systolic function, in cases of advanced coronary artery stenosis, parameters such as ejection fraction (EF) or shortening fiber in the circumferential direction may not be able to detect the relative contribution of these variables in the disruption of blood pumping to the left ventricle (LV) [4].

Left ventricular systolic function can be quantified by physical and mechanical parameters. The use of non-invasive tools in clinical applications is controversial. A new approach to quantify the regional strain of the LV is a two-dimensional speckle tracking echocardiography (2D-STE) method that measures myocardial strain using automated functional imaging (AFI) independent of the tissue angle $[5,6,7]$. Savari et al.[8] showed that strain echocardiography can be used to identify patients with significant coronary artery stenosis. Wall stress is another physical parameter that could be correlated with myocardial oxygen consumption. It plays an essential role in the mechanical behavior of coronary artery circulation. Thus, the distribution of wall stress throughout the cardiac cycle provides a quantitative assessment of left ventricular response and regulation.

The thick wall theory was developed by Ghista-Sandler. This model is a three-dimensional elasticity of LV in which the shape of the LV varies during systole and diastole phases [9]. Elasticity describes the mechanical behavior of the LV muscle during systole and diastole phases. It may be suggested as a diagnostic parameter.

In this study, the regional biomechanical analysis is studied. A mathematical model (Ghista-Sandler) is adopted to estimate ventricular wall stress. The accuracy of the model is assayed, and the strain is calculated to differentiate between control and CAD participants by 2D-STE analysis. These non-invasive variables can recognize abnormalities and quantify left ventricular systolic function for CAD patients before angioplasty. The aim of this study was to calculate the diagnostic value of regional stress and strain parameters for differentiating significant CAD patients from non-significant CAD.

\section{Materials And Methods}

- Study population: Initially, 100 patients ( $58 \pm 8 \mathrm{yr}$, male) CAD with suspected acute coronary syndrome who were candidates for angiography and angioplasty were enrolled. The inclusion criteria for the patients were: chest pain in the last three days, and LVEF $\geq 50 \%$ with preserved systolic function. The exclusion criteria were: previous myocardial infarction, previous heart surgery, more than mild heart valve disease, hypertension or diabetes, advanced renal failure (estimated glomerular filtration rate $<30$ $\mathrm{ml} / \mathrm{min}$ ), left ventricular dysfunction ( $\mathrm{LVEF}<30 \%)$, atrial fibrillation with a heart rate of $>100$ beats per minute or a persistent arrhythmia that could affect image analysis, and images that were unavailable in one or more views. After hospitalization, diagnostic electrocardiograms (ECG) were obtained from the patients. Unstable chest pain was diagnosed by routine laboratory testing with cardiac troponin 
levels $>0.112 \mathrm{mg} / \mathrm{l}$. Echocardiographic examination was performed for all the patients before angiography. The study was approved by the Ethics Committee of Tarbiat Modares University and Shahid Rajaei Hospital (approval No. 1397.095 and 1398.091). The study period was from March 2018 to January 2020, and all of the patients signed an informed consent form.

- Conventional echocardiography: Echocardiography examination was performed $24 \mathrm{~h}$ before angiography using a Philips Affiniti 50 system (Philips Healthcare, Andover, Massachusetts, USA) equipped with a cardiac transducer sector S4-2 (2-4 MHz) with 80 elements, $20.3 \mathrm{~mm}$. Blood pressure was recorded in the left brachial artery in the supine position using a semiautomatic device (Riester 0124, Jungingen, Germany). The systolic stress of the LV was estimated non-invasively by systolic blood pressure. All the patients lay down in the position of left lateral decubitus and were attached to the electrocardiography (ECG) device. 2D-echocardiography was superimposed in three consecutive cycles on the images. Each plane was obtained in three consecutive cardiac cycles in breath-hold with 60-100 frames/s. The end-diastolic phase was initiated at the peak R-wave of the ECG. The end-systolic phase was marked as aortic valve closure in the apical view of the long axis, and grayscale images were obtained with B-mode second harmonic imaging and using the transmitted and received frequencies (1.9/4 MHz). 2D-echocardiographic images were taken with standard parasternal short-axis views and two, three, and four-chamber apical views in accordance with the guidelines of the American Society of Echocardiography (ASE) and European Association of Cardiovascular Imaging (EACVI) [10]. To obtain circular parasternal views of the left ventricular wall at three levels, the position of the transducer was changed by different intercostal spaces. The base, mid, and apex levels in the short-axis view were defined respectively at mitral valve level, at the level of papillary muscle, and distal LV without observation of papillary muscle. Circumferential strain and transverse diameter were provided by the parasternal short-axis view. In the long-axis view, basal and apical levels [11] were displayed as the 1/3 highest and lowest point of the LV axis, respectively (Fig. 1).

In the LV long-axis view, the LV end-diastolic dimension and end-systolic dimension were measured and fractional shortening (FS) was calculated. The left ventricular ejection fraction (LVEF) was calculated by Simpson's biplane method and based on the end-systolic volume and end-diastolic volume in 2D images [10]. The data were digitally stored in DICOM and AVI formats on a memory drive and transferred to a PC for subsequent processing.

- Coronary angiography: All the patients underwent angiography within $24 \mathrm{hr}$ after echocardiography examination according to specific instructions [12]. An interventional cardiologist evaluated angiographic findings. Coronary artery stenosis was visually estimated in two planes perpendicular to each other. The location of the lesion was assessed, and the percent of stenosis diameter for each coronary lesion was determined based on the American Heart Association classification [12]. We selected CAD patients that includes the LAD territory. The patients were divided into two groups according to the results of coronary artery angiography (CAG): one or two-vessel stenosis (stenosis only in one or two vessels; LAD (left anterior descending), LAD+RCA (right coronary artery), or LAD+LCX (left circumflex), and control group (subjects with no CAD). Initially, 100 patients with suspected CAD were enrolled. Echocardiographic 
examination was performed for all the patients before angiography. Five patients, due to personal reasons, did not consent to CAG. Also, five patients, because of poor imaging quality and motion artifacts, were excluded from the study. Ninety patients were evaluated with 2D-STE before CAG. Sixtyfour cases $(71.11 \%)$, with more than $70 \%$ coronary stenosis, were successfully treated with DES (drugeluting stents). In two cases (2.22\%), due to stenosis, 3 vessel disease patients were not included for PCl, they were a candidate for CABG (coronary artery bypass grafting). Twenty-four cases $(26.67 \%$ ) had nonsignificant stenosis and did not undergo angioplasty. Thus, the final sample included 64 patients treated with DES and 24 patients in the control group. Significant CAD patients used medications such as $\beta$-blockers, angiotensin II receptor blockers, statins, and nitrates.

- Theory of ellipsoidal thick-walled model: Ghista and Sandler 3D elasticity model [9] is a 3D elasticity of LV in which the shape of the LV varies during systolic and diastolic phases. In the diastolic phase, the oval shape becomes smaller and the internal cavity becomes larger. During the systolic phase, LV is thicker and more ellipsoidal. Varying wall thickness and geometrical cavity of LV represent more accurate assessment and are closer to the real shape of LV and the clinical situation. The myocardium is assumed with an elastic, homogeneous, and isotropic material. The geometrical data employed in the evaluation of the stresses were obtained from $2 \mathrm{D}$ echocardiography.

- Regional wall stress: For the distribution of regional wall stress in equatorial, the ellipsoid thick-walled model was considered (Ghista-Sandler). With a cylindrical coordinate system $(r, \theta, z)$, we can show the equatorial surface of the closed elliptical shell [13], where $L$ and $W$ are the semi-major and semi-minor axes of the ellipsoid, respectively (Fig. 2).

The Ghista-Sandler model [9] is based on the ellipsoidal thick-shell theory and the 3D left ventricular geometry is simulated with a quasi-ellipsoidal model. For the geometrical model to be matched with the actual model in size, the value of "a" factor (size parameter of the model) is also important. Consequently, in this model, the stress distribution at the equatorial level for radial, longitudinal, and circumferential directions was obtained from the following equations [9]. 


$$
\sigma_{r r}=-\frac{\frac{4 A}{a^{2}}\left(2 d_{c}^{2}+1\right)}{d_{c}^{2}\left(d_{c}^{2}+1\right)^{\frac{3}{2}}}+B
$$

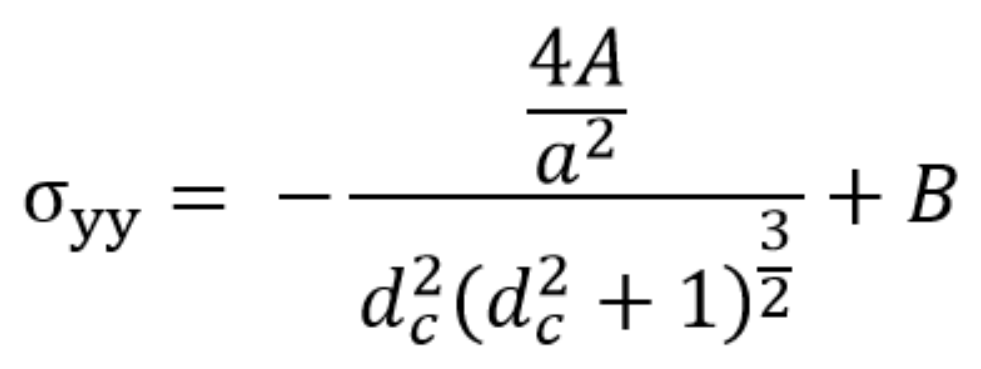

(2)

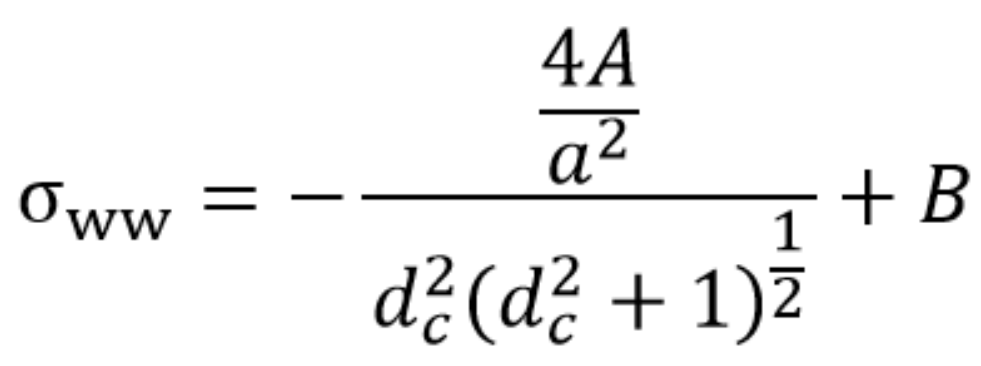

(3)

$\sigma_{\mathrm{rr}}, \sigma_{\mathrm{yy}}$, and $\sigma_{\mathrm{ww}}$ are radial, longitudinal, and circumferential stresses, respectively; $\mathrm{A}$ and $\mathrm{B}$ are intensity stress parameters; $\mathrm{W}$ and $\mathrm{H}$ are width and wall thickness, respectively; and $\mathrm{dc}$ is defined as follows:

\section{$\mathrm{d}_{\mathrm{c}}=(\mathrm{W}+\mathrm{H}) / 2 \mathrm{a}$}

To estimate the stress based on this model, geometrical parameters, including cavity dimensions and ventricular wall thickness, were measured by echocardiography images. Off-line analysis was performed by the Philips DICOM Viewer analysis software, version 3.0 (Philips Healthcare, the Netherlands). The anterior and inferoseptal wall thicknesses and length of the LV were measured in the frozen views of apical four- and two-chamber in the peak systolic phase. The transverse diameter of the basal level was considered in the standard LV short-axis view (Fig. 3), so longitudinal, radial, and circumferential stresses were calculated by the given formulas.

- Speckle tracking echocardiography for strain analysis: The strain is a dimensionless quantity. Because of the 3D geometry of the heart and the orientation of myofibrils, the strain is defined in three directions (longitudinal, radial, and circumferential). Peak GLS (global longitudinal strain) and GCS (global circumferential strain) describe the relative length change of the LV myocardium between the enddiastolic phase and the end-systolic phase [10]. Positive strain indicates lengthening, and negative strain indicates shortening. Longitudinal and circumferential strain values are negative, and radial strain values are positive. All images were analyzed offline before having angiographic information on the central 
computer using the QLAB software version 12 (advanced quantification software, cardiology QLAB Philips Healthcare, Andover, the Netherlands). Myocardial function as a strain analysis in the form of frame-frame was evaluated during the cardiac cycle by semi-automatic tracking of acoustic markers. Endocardial borders were automatically traced in all frames of 2D images for each cycle at the end of systole, and poor tracking segments were manually adjusted. The QLAB software divided the left ventricular wall into 18 segments for three levels (base, mid, and apex), and every three levels were divided into six segments (anteroseptal, inferoseptal, anterior, anterolateral, inferolateral, and inferior wall) $[10,14]$. Anteroseptal and anterior walls are supplied by the LAD artery, inferolateral and anterolateral by the LCX, and inferior and inferoseptal by the RCA artery (Fig. 4).

Longitudinal strain in the apical view and circumferential strain in the parasternal view of global longitudinal strain segments were calculated between aortic valve opening and closing, in the peak systolic phase. In this study, CAD patients had LAD and RCA stenosis, therefore, base anterior and inferoseptal segments were selected. An example of a strain curve is depicted in a two-chamber view for six segments in Fig. 5.

- Elastic modulus: The elastic modulus of the LV is a ratio of stress to strain and explains the functional and structural system of LV. For determination of the elastic modulus of LV muscle, passive stress in the geometrical model and strain by STE was calculated. Anterior and inferoseptal elastic moduli were estimated in the direction of longitudinal and circumferential in the systolic phase.

- Statistical analysis: All the data were presented as mean \pm standard deviation (SD). A comparison of differences between the variables in two groups was performed with a t-test at the significance level of 0.05. The data were tested for normality of distribution by the Kolmogorov-Smirnov (K-S) test. Sample size was estimated on 24 samples, in each group with a confidence level of $95 \%$ and test power of $85 \%$. P-value less than 0.05 was chosen as the levels of statistical significance. The receiver operating characteristic (ROC) curve (the plot of test sensitivity versus 1-specificity) as a nonparametric analysis, as well as the area under the curve (AUC), was used. The ROC curve was employed to determine the quality of the diagnostic modality to establish cut-off points for optimal sensitivity and specificity. Intraobserver and interobserver variabilities were the differences between the measurements expressed as a percentage of the error of the means. Reproducibility was analyzed with intra-class correlation (ICC). All the statistical analyses were performed using the SPSS software package (SPSS Inc. Chicago, IL, USA).

\section{Results}

The baseline demographics and routine echocardiographic for the control group and PCI patients are summarized in Table 1. There were no significant differences in age, heart rate (HR), body mass index (BMI), fractional shortening (FS), cardiac index (Cl), and stroke index (SI). Compared with the control group, systolic and diastolic blood pressure was higher, but the difference was not statistically significant. The LV end-diastolic volume and end-systolic volume in the PCl group were higher compared with the control group $(P<0.05)$ and it was statistically significant but clinically had no diagnostic value. 
The early mitral inflow velocity (E) wave and early diastolic mitral annular lateral tissue velocity (e') were not statistically significant, but the E/e' ratio was statistically significant $(P<0.05)$.

Table 1. Mean $\pm S D$ of demographic and echocardiographic characteristics of the control and PCl groups.

\begin{tabular}{|c|c|c|c|}
\hline P-value & $\begin{array}{l}\mathrm{PCl} \text { group } \\
(\mathrm{n}=64)\end{array}$ & $\begin{array}{l}\text { Control } \\
(n=24)\end{array}$ & Variable \\
\hline 0.946 & $57.73 \pm 9.24$ & $57 \pm 9$ & Age (y) \\
\hline 0.729 & $24.71 \pm 2.51$ & $24.91 \pm 2.54$ & $\mathrm{BMI}\left(\mathrm{kg} / \mathrm{m}^{2}\right)$ \\
\hline 0.301 & $83.03 \pm 7.85$ & $81.21 \pm 5.61$ & $\mathrm{DBP}(\mathrm{mmHg})$ \\
\hline 0.345 & $135.39 \pm 9.15$ & $133.37 \pm 8.04$ & $\mathrm{SBP}(\mathrm{mmHg})$ \\
\hline 0.331 & $72.29 \pm 5.77$ & $71.00 \pm 4.83$ & HR (beats/min) \\
\hline$\underline{0.006}$ & $45.30 \pm 8.99$ & $39.85 \pm 4.68$ & LVESV(ml) \\
\hline$\underline{0.037}$ & $111.73 \pm 21.49$ & $102.02 \pm 10.08$ & LVEDV (ml) \\
\hline$\underline{0.012}$ & $59.43 \pm 2.22$ & $60.91 \pm 2.84$ & $\mathrm{EF} \%$ \\
\hline 0.758 & $23.75 \pm 6.22$ & $24.20 \pm 5.50$ & FS\% \\
\hline 0.264 & $2274.31 \pm 594.94$ & $2426.40 \pm 475.10$ & $\mathrm{Cl}\left(\mathrm{ml} / \mathrm{min} \cdot \mathrm{m}^{2}\right)$ \\
\hline 0.081 & $31.29 \pm 7.03$ & $34.16 \pm 6.14$ & $\mathrm{SI}\left(\mathrm{ml} / \mathrm{m}^{2}\right)$ \\
\hline 0.910 & $69.61 \pm 17.34$ & $69.17 \pm 14.39$ & $\mathrm{E}(\mathrm{cm} / \mathrm{s})$ \\
\hline 0.060 & $7.86 \pm 2.35$ & $8.94 \pm 2.63$ & $\mathrm{e}^{\prime}$ lateral $(\mathrm{cm} / \mathrm{s})$ \\
\hline$\underline{0.044}$ & $9.29 \pm 2.53$ & $8.12 \pm 1.91$ & E/e' \\
\hline
\end{tabular}

$B M I$, body mass index; DBP, diastolic blood pressure;SBP, systolic blood pressure; HR, heart rate; LVESV, left ventricle end-systolic volume; $L V E D V$, left ventricle end-diastolic volume; EF, ejection fraction; FS, fractional shortening; Cl; cardiac index; SI, stroke index; E, mitral early diastole velocity; e', peak mitral annular velocity during early diastole. Bold values mean statistically significant.

Angiographic features are given in Table 2. Based on the angiographic result, stenosis was divided into two groups: the $\mathrm{PCl}$ group ( $\mathrm{n}=64,72.73 \%$ ) with significant stenosis $>70 \%$ in which stenosis was located in 25 patients (39.06\%) only in LAD, in 23 patients (35.93\%) in both LAD and RCA, and in 16 patients (25\%) in both LAD and LCX; so, all PCI patients suffered from LAD stenosis and were candidates for DES; and the control group $(n=24,27,27 \%)$ that did not need angioplasty.

Table 2. Number (percentage) of angiographic characteristics of control and PCl patients. 


\begin{tabular}{|lll|}
\hline PCl group & Control group & \\
$64(72.73 \%)$ & $24(27.27 \%)$ & \\
\hline $25(39.06 \%)$ & - & 1 vessel (LAD) \\
$23(35.93 \%)$ & - & 2 vessels (LAD and RCA) \\
$16(25.00 \%)$ & - & 2 vessels (LAD and LCX) \\
\hline
\end{tabular}

$L A D$, left anterior descending artery; $R C A$, right coronary artery; $L C X$, left circumflex

The geometrical data are listed in Table 3. There were significant differences between the control and PCl groups for anterior and inferoseptal wall thickness and transverse wall radius $(p<0.05)$.

Table 3. Mean $\pm S D$ of the geometrical data of control and $\mathrm{PCl}$ groups by $2 \mathrm{D}$ echocardiographic imaging at the end-systolic phase.

\begin{tabular}{|llll|}
\hline P-value & $\begin{array}{c}\mathrm{PCl} \text { group } \\
(\mathbf{n}=\mathbf{6 4})\end{array}$ & $\begin{array}{l}\text { Control group } \\
(\mathbf{n}=\mathbf{2 4})\end{array}$ & Left ventricular $(\mathrm{mm})$ \\
\hline $\mathbf{0 . 0 0 1}$ & $11.65 \pm 0.81$ & $10.74 \pm 0.54$ & Inferoseptal wall thickness \\
\hline $\mathbf{0 . 0 0 1}$ & $11.53 \pm 0.83$ & $10.43 \pm 0.45$ & Anterior wall thickness \\
\hline $\mathbf{0 . 0 0 1}$ & $35.89 \pm 2.74$ & $31.46 \pm 2.74$ & One-half of the LV long axis \\
\hline $\mathbf{0 . 0 0 1}$ & $21.76 \pm 1.83$ & $19.82 \pm 1.69$ & Transverse wall radius \\
\hline
\end{tabular}

Bold values mean statistically significant.

Regional wall stress at ES is shown in Table 4. In the PCl group, for longitudinal and circumferential directions, greater wall stress was observed in anterior (Ant) and inferoseptal (IS) segments of the equatorial at ES compared to the control group. The circumferential wall stress ES in the inferoseptal segment was statistically significant $(p<0.05)$ but Ant circumferential stress was not statistically significant $(p>0.05)$. Longitudinal stress in every two segments was not statistically significant $(p>0.05)$.

Table 4. Mean \pm standard deviation measurement of longitudinal and circumferential wall stress computed from the Ghista-Sandler model of the LV at end-systole for control and PCl groups. 


\begin{tabular}{|lllll|}
\hline $\begin{array}{l}\text { Wall stress } \\
\left(\mathrm{kdyn} / \mathrm{cm}^{2}\right)\end{array}$ & Segments & $\begin{array}{l}\text { Control } \\
(\mathrm{n}=24)\end{array}$ & $\mathrm{PCl}(\mathrm{n}=64)$ & $\begin{array}{l}\mathrm{P} \text { - } \\
\text { value }\end{array}$ \\
\hline Longitudinal & $\begin{array}{l}\text { Base anterior Base } \\
\text { inferoseptal }\end{array}$ & $164.41 \pm 18.20$ & $172.97 \pm 20.81$ & 0.079 \\
\hline Circumferential & $\begin{array}{l}\text { Base anterior Base } \\
\text { inferoseptal }\end{array}$ & $155.08 \pm 13.94$ & $163.02 \pm 20.09$ & 0.079 \\
& & $194.58 \pm 19.46$ & $204.93 \pm 24.65$ & 0.068 \\
\hline
\end{tabular}

Bold values mean statistically significant.

As the stenosis of the coronary artery increased, the peak value of strain decreased (Table 5). There was a significant difference in the peak values of anterior and inferoseptal circumferential strain between the $\mathrm{PCl}$ and control groups $(\mathrm{p}<0.05)$. Also, for all groups, circumferential strain was higher than longitudinal strain. Anterior longitudinal strain was significantly reduced $(p<0.05)$, however, inferoseptal longitudinal strain was decreased was not statistically significant $(p>0.05)$.

Table 5. Mean $\pm S D$ regional longitudinal and circumferential strain data of the LV at peak systolic phase for the control and $\mathrm{PCl}$ groups.

\begin{tabular}{|llccl|}
\hline Strain (\%) & segment & Control $(n=24)$ & $P C I(n=64)$ & P-value \\
\hline Longitudinal & Base anterior Base inferoseptal & $-18.14 \pm 2.64$ & $-16.28 \pm 3.79$ & 0.029 \\
\cline { 3 - 5 } & & $-17.44 \pm 3.05$ & $-16.40 \pm 5.41$ & 0.374 \\
\hline \multirow{2}{*}{ Circumferential } & Base anterior Base inferoseptal & $-21.71 \pm 4.74$ & $-17.25 \pm 4.22$ & 0.000 \\
\cline { 2 - 5 } & & $-20.58 \pm 3.04$ & $-18.21 \pm 4.04$ & $\mathbf{0 . 0 1 1}$ \\
\hline
\end{tabular}

Bold values mean statistically significant

Compared with a control group, stress/strain response of the PCI group showed higher longitudinal and circumferential stiffness in both anterior and inferoseptal segments (Table 6).

Table 6. Mean $\pm S D$ regional longitudinal and circumferential elastic modulus data of the LV at the peak systolic phase for the control and PCl groups. 


\begin{tabular}{|lllll|}
\hline $\begin{array}{l}\text { Elastic modulus } \\
\left(\mathrm{kdyn} / \mathrm{cm}^{2}\right)\end{array}$ & segment & Control $(\mathrm{n}=24)$ & $\mathrm{PCl}(\mathrm{n}=64)$ & $\begin{array}{l}\text { P- } \\
\text { value }\end{array}$ \\
\hline Longitudinal & $\begin{array}{l}\text { Base anterior Base } \\
\text { inferoseptal }\end{array}$ & $921.45 \pm 145.79$ & $1129.84 \pm 333.39$ & $\mathbf{0 . 0 0 4}$ \\
\hline Circumferential & $\begin{array}{l}\text { Base anterior Base } \\
\text { inferoseptal }\end{array}$ & $913.96 \pm 175.67$ & $1099.40 \pm 385.62$ & $\mathbf{0 . 0 2 6}$ \\
& & $935.78 \pm 214.47$ & $1245.99 \pm 283.32$ & $\mathbf{0 . 0 0 0}$ \\
\hline
\end{tabular}

Bold values mean statistically significant

The receiver operator characteristic (ROC) curve was provided whether significant variables (stress, strain, and elastic modulus) could predict PCl patients (Table 7 and Fig. 6). All the presenting results were significant at a $95 \%$ confidence level $(p<0.05)$.

ROC analyses showed that the AUC (0.80) for anterior circumferential elastic modulus was superior to other variables. ROC curves for inferoseptal circumferential stress ( $A \cup C=0.66$ ), anterior longitudinal strain (AUC=0.66), anterior circumferential strain ( $A \cup C=0.76)$, inferoseptal circumferential strain $(A \cup C=0.675)$, inferoseptal circumferential elastic modulus $(A U C=0.74)$, anterior longitudinal elastic modulus $(A \cup C=0.67)$ and inferoseptal longitudinal elastic modulus (AUC $=0.64)$ were observed for discriminating the $\mathrm{PCl}$ group (Table 7 and Fig. 6 a-c).

The optimal cutoff value for anterior circumferential elastic modulus was $964.02 \mathrm{kdyn} / \mathrm{cm}^{2}$ with a sensitivity of $78.1 \%$ and a specificity of $62.5 \%$ for the identification of PCI patients, and inferoseptal circumferential elastic modulus was $945.43 \mathrm{kdyn} / \mathrm{cm}^{2}$ with a sensitivity of $70.3 \%$ and a specificity of $75 \%$ identified PCI group. Circumferential elastic modulus had higher sensitivity and specificity than longitudinal elastic modulus for differentiating the $\mathrm{PCl}$ group from the control group. ROC analysis showed that the elastic modulus parameter was powerful predictor of $\mathrm{PCl}$ patients.

Table 7. Analysis of ROC curve for strain, stress and elastic modulus parameters 


\begin{tabular}{|c|c|c|c|c|c|}
\hline Parameter & Segment & $\operatorname{AUC}(\mathrm{Cl})$ & $\begin{array}{l}\text { cut off } \\
\text { value }\end{array}$ & $\begin{array}{l}\text { Sensitivity } \\
\text { (\%) }\end{array}$ & $\begin{array}{l}\text { Specificity } \\
\text { (\%) }\end{array}$ \\
\hline \multirow[t]{6}{*}{ Strain (\%) } & \multirow[t]{2}{*}{ anterior circumferential } & 0.761 & 19.42 & 73.4 & 62.5 \\
\hline & & $\begin{array}{l}(0.655- \\
0.866)\end{array}$ & & & \\
\hline & \multirow{2}{*}{$\begin{array}{l}\text { inferoseptal } \\
\text { circumferential }\end{array}$} & 0.675 & 19.97 & 68.8 & 66.7 \\
\hline & & $\begin{array}{l}(0.558- \\
0.792)\end{array}$ & & & \\
\hline & \multirow[t]{2}{*}{ anterior longitudinal } & 0.657 & 17.82 & 67.2 & 66.7 \\
\hline & & $\begin{array}{l}(0.542- \\
0.772)\end{array}$ & & & \\
\hline \multirow{2}{*}{$\begin{array}{l}\text { Stress } \\
\left(\mathrm{kdyn} / \mathrm{cm}^{2}\right)\end{array}$} & \multirow{2}{*}{$\begin{array}{l}\text { inferoseptal } \\
\text { circumferential }\end{array}$} & 0.664 & 189.37 & 67.2 & 54.2 \\
\hline & & $\begin{array}{l}(0.542- \\
0.787)\end{array}$ & & & \\
\hline \multirow{8}{*}{$\begin{array}{l}\text { Elastic modulus } \\
\left(\mathrm{kdyn} / \mathrm{cm}^{2}\right)\end{array}$} & \multirow[t]{2}{*}{ anterior circumferential } & 0.800 & 964.02 & 78.1 & 62.5 \\
\hline & & $\begin{array}{l}(0.702- \\
0.898)\end{array}$ & & & \\
\hline & \multirow{2}{*}{$\begin{array}{l}\text { inferoseptal } \\
\text { circumferential }\end{array}$} & 0.736 & 945.43 & 70.3 & 75.0 \\
\hline & & $\begin{array}{l}(0.624- \\
0.848)\end{array}$ & & & \\
\hline & \multirow[t]{2}{*}{ anterior longitudinal } & 0.669 & 925.15 & 65.6 & 58.3 \\
\hline & & $\begin{array}{l}(0.557- \\
0.780)\end{array}$ & & & \\
\hline & \multirow[t]{2}{*}{ inferoseptal longitudinal } & 0.638 & 919.78 & 59.4 & 45.8 \\
\hline & & $\begin{array}{l}(0.521- \\
0.755)\end{array}$ & & & \\
\hline
\end{tabular}

AUC, area under the curve; $\mathrm{Cl}$ : 95\% confidence interval

Reproducibility was assessed in 10 subjects for the $\mathrm{PCl}$ group. All strain parameters displayed the intraclass correlation coefficient (ICC) values $>0.90$ with good interobserver and intraobserver. ICC of anterior longitudinal strain, inferoseptal longitudinal strain, anterior circumferential strain, and inferoseptal circumferential strain for inter-observer was $0.944,0.949,0.986$, and 0.905 respectively. ICC of anterior longitudinal strain, inferoseptal longitudinal strain, anterior circumferential strain, and inferoseptal circumferential strain for intra-observer variability was $0.936 .0 .916,0.956$ and 0.957 , respectively.

\section{Discussion}


In this study, non-invasive physical parameters showing quantitative longitudinal and peripheral myocardial deformity in patients with CAD who were candidates for angioplasty were calculated.

The main finding of this study is that regional circumferential elasticity is a more sensitive and specific parameter (cutoff point, $964.02 \mathrm{kdyn} / \mathrm{cm}^{2}$; sensitivity, $78.1 \%$; specificity, $62.5 \%$ ) than conventional echocardiographic parameters such as ejection fraction and diameters to detect PCl patients. This approach offers new insights and demonstrates the potential of regional analysis in providing details on local mechanics, 2D analysis, and simple geometric modeling. Identifying prospective and non-invasive methods for patients with significant CAD who may undergo revascularization is a challenge. Many patients undergoing coronary angiography display normal results and non-obstructive blood vessels [15].

In the myocardium, the effects of stenosis are defined by the resulting perfusion abnormalities and subsequent contractile defects [16]. In some cases, visual parameters such as regional wall motion abnormalities (RWMA) and EF are not able to detect even patients with high coronary stenosis, and endocardial dysfunction due to ischemia or necrosis is not always determined by these parameters because it is subjective and operator-dependent [17]. Stanton et al. (2009) demonstrated that LVEF could not detect myocardial injury in patients with CAD [18]. EF with Simpson's biplane method indicates changes in left ventricular volume and cannot describe mechanical changes [19].

This study also demonstrated a basic, simple, and non-invasive method for determining the wall stress of the LV at end-systole. Still, mathematical models for the simulation of the left ventricular cavity and determining wall stress need advanced calculation and further research. This method is successful because echo images easily identify the dimensions of the data required for calculating stress. There was a correlation between the systolic cuff blood pressure and systolic manometer LV pressure, although there was no significant correlation between the diastolic cuff blood pressure and diastolic manometer blood pressure [20]. The wall stress index is a pure geometric parameter that quantifies the physical response of the LV under different pressures. In this study, a thick-walled ellipsoid model was adopted for wall stress. Table 4 illustrates the comparison of longitudinal, and circumferential stress between two groups. The results showed that stress was higher in the $\mathrm{PCl}$ group than the control group. High stress in the endocardial layer shows that the myocardial oxygen demand is high in the endocardial region at systole. With decreasing myocardial perfusion in the inner region, the oxygen perfusion status against demand mismatch is increased.

In our study, there was no significant difference in longitudinal wall stress between the anterior and inferoseptal segments, but the anterior wall stress was a little greater than inferoseptal wall stress, which was partly due to the heterogeneity of the wall curvature, increased demand for oxygen supply, and decreased vascular perfusion in the anterior wall relative to the inferoseptal wall, that is similar to the result of Deanda et al [21]. In their study, there was a significant difference in wall stress between anterior, lateral, and posterior walls, due to the heterogeneity of the curvature walls. 
It seems that wall stress only changes when the ventricle is not able to compensate for abnormal pressures or volume load. In the study by Hood et al. [22], the mean circumferential wall stress at a specific location of the wall (anterolateral equatorial area) was estimated using the formula presented by Sandler and Dodge.

In this study, inferoseptal circumferential stress was statistically higher than the control group with an AUC of 0.664 can be a mediocre predictor. No studies have been performed to differentiate $\mathrm{PCI}$ patients from the control group by the Ghista-Sandler model. In the study of Yang [23], strain analysis for significant CAD during dobutamine stress echocardiography (DSE) was done, evaluating of strain analysis with administration dobutamine were generated at baseline and peak stress, but in our study stress was calculated after echocardiography imaging without invasive method. Results for maximum wall stress indicated that anatomical changes may play an important role in determining wall stress. The orientation of the myocardial fiber, which is closely related to the ventricular shape, may be important in explaining the increased equatorial stress in cases of abnormalities. Absolute normal values of circumferential stress were higher than longitudinal stress because of differences in the longitudinal and circumferential radius of the curvature. The use of cardiac imaging and modeling provides opportunities for better understanding and evaluating wall stress. Previous studies have elucidated the properties of wall stress and examined their proper analysis to apply these concepts to research [24]. The present study specifically examined the changes of regional longitudinal and circumferential myocardial strain at peak systole in CAD patients. Accordance with Table 5, longitudinal and circumferential strain have decreased in significant CAD patients. There was not a significant difference in inferoseptal longitudinal strain between the $\mathrm{PCl}$ group and the control group $(\mathrm{p}>0.05)$. Anterior and inferoseptal circumferential strain was significantly reduced in CAD patients. Also, longitudinal strain and circumferential strain in both control and $\mathrm{PCl}$ groups were higher than those reported in other studies. These results are approximately similar to those reported by Caspar et al. [25] and Meimoun et al. [26], demonstrating that different global longitudinal strain through different $C A D$ categories have a diagnostic and prognostic value. Table 5 also showed circumferential strain in the endocardium layer of the LV was higher than the longitudinal strain. If the circumferential fiber is affected by the contraction of orthogonal longitudinal fibers along the systole, it will be expected to be shorter and decrease longitudinal dimensions. The ROC analysis showed that we could identify $\mathrm{PCl}$ patients with an appropriate cut-off point for anterior circumferential strain (AUC of 0.761 with sensitivity $73.4 \%$ and specificity $62.5 \%$ ) and (AUC of 0.675 with sensitivity $68.8 \%$ and specificity $66.7 \%$ ) for IS CS. We have shown excellent intra- and inter-observer reproducibility in 2DSTE measurements for ten patients. Our results indicated that the measurement of regional CS by 2D-STE is a significant independent predictor for ventricular function variation. This predictor was superior to more traditional echocardiographic techniques such as LVEF or WMSI (wall motion score index) and slightly superior than regional circumferential stress. We found that $\mathrm{PCI}$ patients with significant CAD had a statistically significant decrease in the threshold of EF $(59.43 \pm 2.22 \% \mathrm{vs}$. control: $60.91 \pm 2.84 \%$; $<0.012$ ), which did not correspond to the results of Yılmaztepe et al. [27].

Our results showed that mechanical changes of left ventricular myocardium in PCI patients were more important than in the control group. Previous study [28] evaluated patients with suspected CAD; they 
observed a significant decrease in global longitudinal strain in patients with significant CAD compared with those having nonsignificant CAD, which was similar to our results but our results were regional. Most studies have evaluated strain globally. Based on a review study [29], 177 patients with suspected CAD were enrolled in one of the reviewed studies. It was found that the mean global longitudinal strain values were $-16.3 \%$ in patients with CAD + and $-19.1 \%$ in patients with CAD. Nucifora et al. [30] studied 182 patients with suspected CAD, and concluded that global longitudinal strain $<-17.4 \%$ may predict significant CAD obstruction ( $>50 \%$ ) with multislice computed tomography with a sensitivity of $83 \%$ and a specificity of $77 \%$. Shimoni et al. [31] examined 97 patients with suspected CAD and found that global longitudinal strain was significantly lower in patients with significant CAD than in patients with nonsignificant CAD, with mean global longitudinal strain values of $-17.3 \%$ vs. $-20.8 \%(p<0.05)$. They also showed that global longitudinal strain $<-19.7 \%$ may predict significant CAD obstruction $(>50 \%)$ with $81 \%$ sensitivity and $67 \%$ specificity. In comparison, Edwards et al.[32] found global longitudinal strain was only a fair predictor of CAD, with an AUC of 0.693 in patients with CAD. They demonstrated that global myocardial work (GMW) was the most powerful predictor of significant CAD with AUC $=0.786$ and was superior to global longitudinal strain. The optimal global longitudinal strain diagnostic cut-off point is quite different from those of previous studies and may depend on clinical features, diastolic function, hemodynamic parameters, various equipment, and the 2D-STE software [28, 33]. However, inferoseptal longitudinal strain, regional longitudinal stress, and anterior circumferential stress were not statistically significant, regional elasticity that is the ratio of stress to strain was significantly increased in both directions for $\mathrm{PCl}$ groups compared with the control group (AUC=0.80 with the sensitivity of $78.1 \%$ and specificity of $62.5 \%$ for anterior circumferential elasticity) and (AUC $=0.736$ with the sensitivity of $70.3 \%$ and specificity of $75 \%$ for inferoseptal circumferential elasticity). Regional passive elastic modulus as an excellent predictor was superior to regional stress and strain parameters. The study of Berry et al. [34] found the elastic modulus of healthy heart tissue was in the range of $10-15 \mathrm{kPa}$, while the elastic modulus of ischemic tissue 14 days after surgery increased around $50 \mathrm{kPa}$. It is very difficult to compare the investigated values of modulus for LV muscle with the obtained values in other methods which are due to differences in the methods used (such as mathematical models and method for strain analysis). The classic values of modulus for postmortem myocardial muscle in relaxation time of muscle fibers are in the range of $0.3-5 \times 10^{4} \mathrm{~N} / \mathrm{m}^{2}$ and increase in the contraction time.

- Limitations of the study: Peak systolic blood pressure only provides global stress values for the entire ventricle. Thus, the regional stress variations of the wall included only geometrical factors. Moreover, local pressure changes were not considered. Only patients with good echocardiographic images could be included and analyzed with STE; thus, it reduced the sample size. One technical limitation was that ST echocardiography depends on frame rate and image resolution. The low frame rate in the speckle pattern causes considerable variation from one frame to another and prevents the precise characterization of regional myocardial motion. In contrast, increasing the frame rate reduces the scan line density and image resolution. Previous authors have confirmed that contrast-enhanced MRI, positron emission tomography (PET), and gated SPECT are beneficial quantitative methods for defining myocardial survival. Although these techniques may be used as a gold standard for analysis, high costs and limited 
accessibility limit their routine using in ischemic patients. Because the validity of the ST software has already been compared with MRI and clinically and experimentally tested, no comparison was made with the MRI technique. The estimation of wall stress in boundary conditions was performed less accurately by these models. The ventricle is a complex structure that could not be easily modeled in this study. Although thick-walled models are similar in their assumptions, the results are different.

\section{Conclusion}

This study established a basis for analyzing the local curvature in $\mathrm{PCl}$ candidates. Physical parameters can reflect the pathology based on non-perfused damaged heart segments. Also, the regional elastic modulus is a powerful predictor and non-invasive tools can offer quantitative insight into myocardial function. This result may improve decision-making for the selection of

\section{Declarations}

\section{Compliance with Ethical Standards}

Authors declare that they have no conflict of interest.

All procedures performed in studies involving human participants were in accordance with the ethical standards of the ethical committee of Tarbiat Modares University approved the protocol of the study and with the 1964 Helsinki declaration and its later amendments or comparable ethical standards. Informed consent was obtained from all individual participants included in the study.

\section{Acknowledgment}

This study was approved by Faculty of Medical Sciences, Tarbiat Modares University. We wish to thank staffs of Echocardiography Research Center, emergency room and Cath Lab of Rajaie cardiovascular medical and research center.

\section{Disclosures}

None.

\section{Authors' contributions}

ZS Ahmadi, M. Mokhtari-Dizaji, deigned the research, acquired and analyzed the data, wrote the manuscript, reviewed the manuscript. A. Sadeghpour, H. Khesali, A. Firouzi contributed to gathering and analyzing data, reviewed the manuscript. The authors read and approved the final manuscript.

\section{Funding}

It had no funds. 
Availability of data and materials

The datasets used and/or analyzed during the current study are available from the corresponding author on reasonable request.

\section{Consent for publication}

Not applicable.

\section{Competing interests}

The authors declare that they have no competing interests.

\section{Author details}

${ }^{1}$ Department of Medical Physics, Faculty of Medical Sciences, Tarbiat Modares University, Tehran, Iran, ${ }^{2}$ Echocardiography Research Center, Rajaie Cardiovascular Medical and Research Center, Iran University of Medical Sciences, Tehran, Iran, ${ }^{3}$ Cardiovascular Intervention Research Center, Rajaie Cardiovascular Medical and Research Center, Iran University of Medical Sciences, Tehran, Iran

\section{References}

1. Doenst T, Haverich A, Serruys P, Bonow RO, Kappetein P, Falk V, Velazquez E, Diegeler A, Sigusch H. $\mathrm{PCl}$ and $\mathrm{CABG}$ for treating stable coronary artery disease. JACC review topic of the week. J Am Coll Cardiol 2019; 73(8): 964-976.

2. Cameli M, Mondillo S, Galderisi M, Mandoli GE, Ballo P, Nistri S, Capo V, D'Ascenzi F, D'Andrea A, Esposito R, Gallina S. Speckle tracking echocardiography: A practical guide. G Ital Cardiol 2017; 18(4): 253-269.

3. Jabari A, Mokhtari-Dizaji M, Arab-Bafrani Z, Mosavi E, Mahani L, Hashemi M.M. Assessment of left ventricular torsion in long axis view in patients with chronic stenosis of coronary arteries. Caspian J Intern Med 2020; 11(1): 21-27.

4. Schroeder J, Hamada S, Gründlinger N, Rubeau T, Altiok E, Ulbrich K, Keszei A, Marx N, Becker M. Myocardial deformation by strain echocardiography identifies patients with acute coronary syndrome and non-diagnostic ECG presenting in a chest pain unit: A prospective study of diagnostic accuracy. Clin Res Cardiol 2016;105(3): 248-256.

5. Arab-Baferani Z, Mokhtari-Dizaji M, Roshanali F. Extraction of left-ventricular torsion angle from the long-axis view by block-matching algorithm: Comparison with the short-axis view. Ultrasonics 2013; 53(2): 552-560.

6. D'Andrea A, Cocchia R, Caso P, Riegler L, Scarafile R, Salerno G, Golia E, Di Salvo G, Calabrò P, Bigazzi MC, Liccardo B. Global longitudinal speckle-tracking strain is predictive of left ventricular remodeling 
after coronary angioplasty in patients with recent non-ST elevation myocardial infarction. Int J Cardiol 2011; 153(2): 185-191.

7. Ejlersen JA, Poulsen SH, Mortensen J, May O. Diagnostic value of layer-specific global longitudinal strain during adenosine stress in patients suspected of coronary artery disease. Int $\mathrm{J}$ Cardiol Imaging 2017; 33(4): 473-480.

8. Sarvari SI, Haugaa KH, Zahid W, Bendz B, Aakhus S, Aaberge L, Edvardsen T. Layer-specific quantification of myocardial deformation by strain echocardiography may reveal significant CAD in patients with non-ST-segment elevation acute coronary syndrome. JACC: Cardiovasc Imag 2013; 6(5): 535-544.

9. Zhong L, Ghista D, Tan R. Left ventricular wall stress compendium. Comput Method Biomech 2012; 15(10): 1015-1041.

10. Lang RM, Badano LP, Mor-Avi V, Afilalo J, Armstrong A, Ernande L, Flachskampf FA, Foster E, Goldstein SA, Kuznetsova T, Lancellotti P. Recommendations for cardiac chamber quantification by echocardiography in adults: An update from the American Society of Echocardiography and the European Association of Cardiovascular Imaging. Eur Heart J Cardiovasc Imag 2015; 16(3): 233-271.

11. Luo X, Cao T, Li Z, Duan Y. A preliminary study on the evaluation of relationship between left ventricular torsion and cardiac cycle phase by two-dimensional ultrasound speckle tracking imaging. Int J Cardiovasc Imag 2009; 25(6): 559-568.

12. Scanlon PJ, Faxon DP, Audet AM, Carabello B, Dehmer GJ, Eagle KA, Legako RD, Leon DF, Murray JA, Nissen SE, Pepine CJ. ACC/AHA guidelines for coronary angiography: executive summary and recommendations: a report of the American College of Cardiology/American Heart Association Task Force on Practice Guidelines (Committee on Coronary Angiography) developed in collaboration with the Society for Cardiac Angiography and Interventions. Circulation 1999; 99(17): 2345-2357.

13. Zhong L, Su Y, Yeo SY, Tan RS, Ghista DN, Kassab G. Left ventricular regional wall curvedness and wall stress in patients with ischemic dilated cardiomyopathy. Am J Physiol Heart Circ Physiol 2009; 296(3): 573-584.

14. Zuo HJ, Yang XT, Liu QG, Zhang Y, Zeng HS, Yan JT, Wang DW, Wang H. Global longitudinal strain at rest for detection of coronary artery disease in patients without diabetes mellitus. Curr Med Sci 2018; 38(3): 413-421.

15. Shah R, Yow E, Jones WS, Kohl III LP, Kosinski AS, Hoffmann U, Lee KL, Fordyce CB, Mark DB, Lowe A, Douglas PS. Comparison of visual assessment of coronary stenosis with independent quantitative coronary angiography: findings from the Prospective Multicenter Imaging Study for Evaluation of Chest Pain (PROMISE) trial. Am. Heart J 2017; 184(1): 1-9.

16. Collier P, Phelan D, Klein A. A test in context: Myocardial strain measured by speckle-tracking echocardiography. J. Am. Coll. Cardiol 2017; 69(8): 1043-1056.

17. Liu C, Li J, Ren M, Wang ZZ, Li ZY, Gao F, Tian JW. Multilayer longitudinal strain at rest may help to predict significant stenosis of the left anterior descending coronary artery in patients with suspected non-ST-elevation acute coronary syndrome. Int J Cardiovasc Imag 2016; 32(12): 1675-1685. 
18. Stanton T, Leano R, Marwick TH. Prediction of all-cause mortality from global longitudinal speckle strain: comparison with ejection fraction and wall motion scoring. Circ Cardiovasc Imag 2009; 2(5): 356-364.

19. Li L, Zhang PY, Ran H, Dong J, Fang LL, Ding Q-S. Evaluation of left ventricular myocardial mechanics by three-dimensional speckle tracking echocardiography in the patients with different graded coronary artery stenosis. Int J Cardiovas Imag 2017; 33(10): 1513-1520.

20. Moladoust H, Mokhtari-Dizaji M, Ojaghi-Haghighi Z. Evaluation of left anterior descending coronary artery stenosis severity from myocardial end-diastolic wall stress estimated by Tissue Doppler imaging. J Clin Ultrasound 2013; 41(5): 297-304.

21. DeAnda Jr A, Komeda M, Moon MR, Green GR, Bolger AF, Nikolic SD, Daughters GT, Miller DC. Estimation of regional left ventricular wall stresses in intact canine hearts. Am J Physiol-Heart $C$ 1998; 275(5): 1879-1885.

22. Sandler H, Dodge HT. Left ventricular tension and stress in man. Circ Res 1963; 13(2): 91-104.

23. Yang LT, Kado Y, Nagata Y, Otani K, Otsuji Y, Takeuchi M. Strain imaging with a bull's-eye map for detecting significant coronary stenosis during dobutamine stress echocardiography. J Am Soc Echocardiogr 2017; 30(2): 159-167.

24. Zhao X, Tan RS, Tang HC, Teo SK, Su Y, Wan M, Leng S, Zhang JM, Allen J, Kassab GS, Zhong L. Left ventricular wall stress is sensitive marker of hypertrophic cardiomyopathy with preserved ejection fraction. Front Physiol 2018; 28(9): 250.

25. Caspar T, Samet H, Ohana M, Germain P, El Ghannudi S, Talha S, Morel O, Ohlmann P. Longitudinal 2D strain can help diagnose coronary artery disease in patients with suspected non-ST-elevation acute coronary syndrome but apparent normal global and segmental systolic function. Int $\mathrm{J}$ Cardiol 2017; 1(236): 91-94.

26. Meimoun P, Abouth S, Clerc J, Elmkies F, Martis S, Luycx-Bore A, Boulanger J. Usefulness of twodimensional longitudinal strain pattern to predict left ventricular recovery and in-hospital complications after acute anterior myocardial infarction treated successfully by primary angioplasty. J Am Soc Echocardiog 2015; 28(11): 1366-1375.

27. Yılmaztepe MA, Uçar FM. Layer-specific strain analysis in patients with suspected stable angina pectoris and apparently normal left ventricular wall motion. Cardiovascular ultrasound 2018; 1(16): 16-25.

28. Radwan H, Hussein E. Value of global longitudinal strain by two dimensional speckle tracking echocardiography in predicting coronary artery disease severity. Egypt Heart J 2017; 69(2): 95-101.

29. Norum IB, Ruddox V, Edvardsen T, Otterstad JE. Diagnostic accuracy of left ventricular longitudinal function by speckle tracking echocardiography to predict significant coronary artery stenosis. A systematic review. BMC Med Imag 2015; 15(1): 1-12.

30. Nucifora G, Schuijf JD, Delgado V, Bertini M, Scholte AJ, Ng AC, van Werkhoven JM, Jukema JW, Holman ER, van der Wall EE, Bax JJ. Incremental value of subclinical left ventricular systolic 
dysfunction for the identification of patients with obstructive coronary artery disease. Am. Heart J 2010; 159(1): 148-157.

31. Shimoni S, Gendelman G, Ayzenberg O, Smirin N, Lysyansky P, Edri O, Deutsch L, Caspi A, Friedman Z. Differential effects of coronary artery stenosis on myocardial function: The value of myocardial strain analysis for the detection of coronary artery disease. J Am Soc Echocardiogr 2011; 24(7): 748757.

32. Edwards NF, Scalia GM, Shiino K, Sabapathy S, Anderson B, Chamberlain R, Khandheria BK, Chan J. Global myocardial work is superior to global longitudinal strain to predict significant coronary artery disease in patients with normal left ventricular function and wall motion. J Am Soc Echocardiogr 2019; 32(8): 947-957.

33. Dohi K, Sugiura E, Ito M. Utility of strain-echocardiography in current clinical practice. J Echocardiogr 2016; 14(2): 61-70.

34. Berry MF, Engler AJ, Woo YJ, Pirolli TJ, Bish LT, Jayasankar V, Morine KJ, Gardner TJ, Discher DE, Sweeney HL. Mesenchymal stem cell injection after myocardial infarction improves myocardial compliance. Am J Physiol Heart Circ Physiol 2006; 290(6): H2196-2203.

\section{Figures}




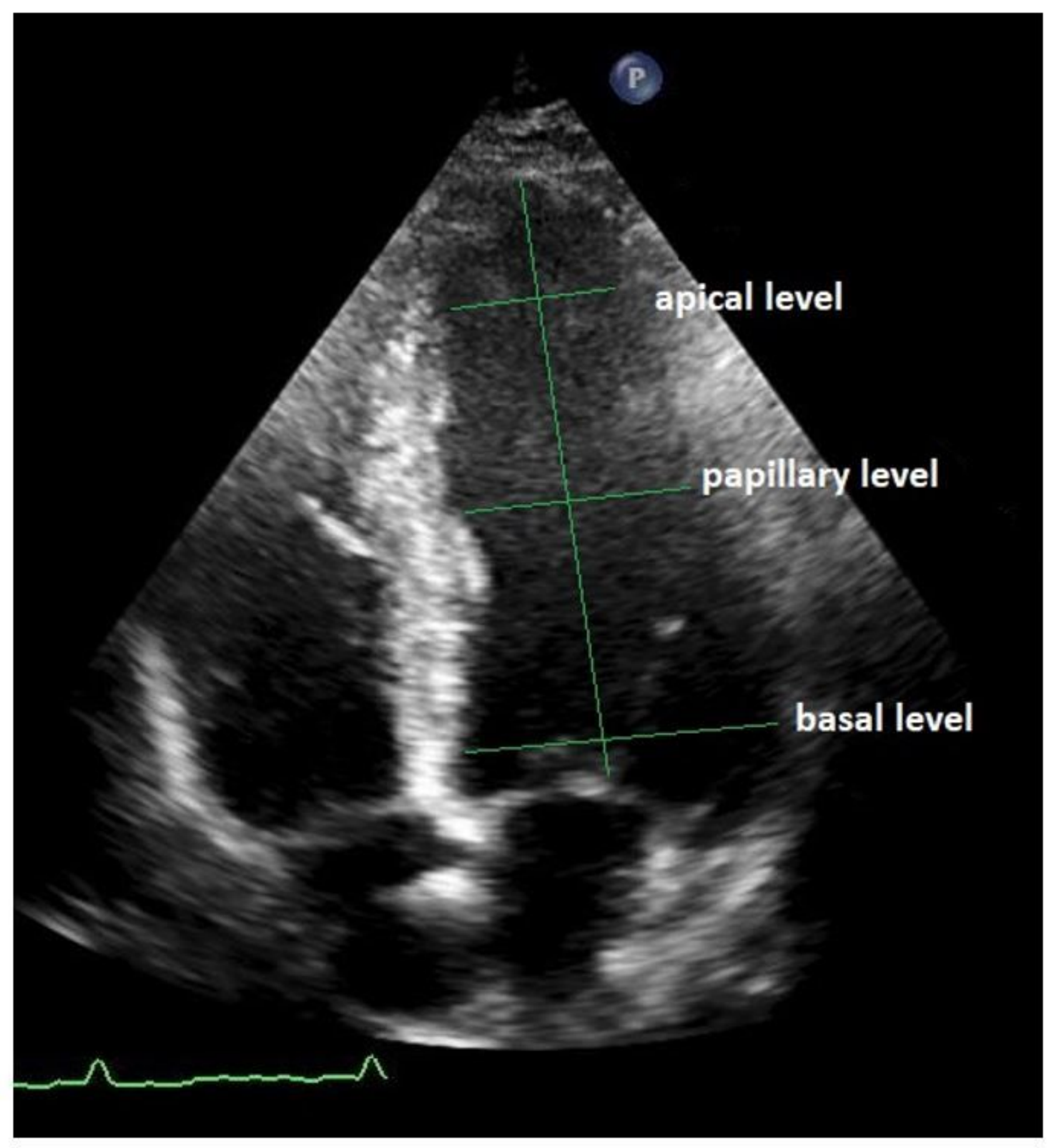

Figure 1

Three levels of LV; basal, papillary and apical levels. 


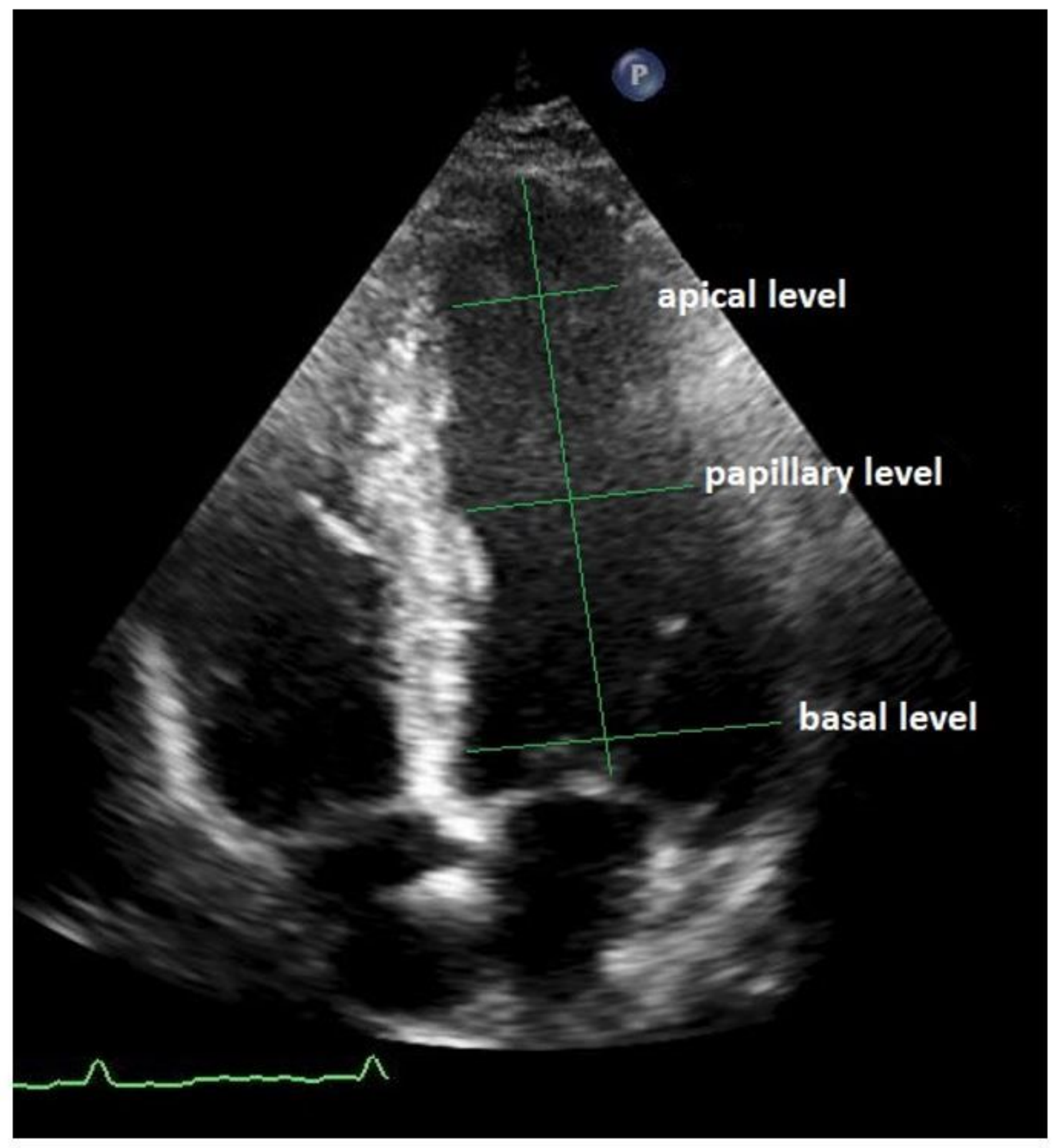

Figure 1

Three levels of LV; basal, papillary and apical levels. 


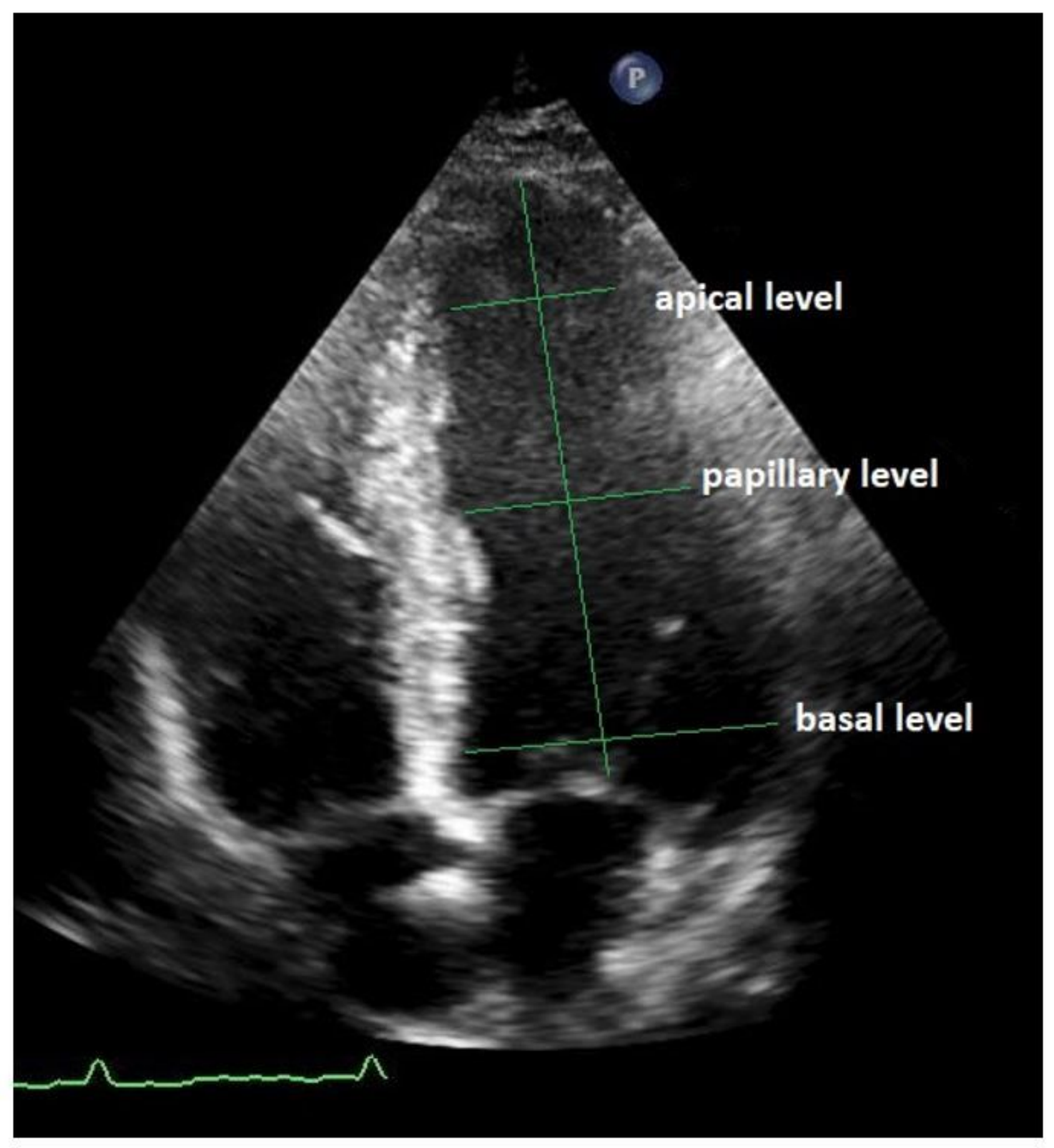

Figure 1

Three levels of LV; basal, papillary and apical levels. 


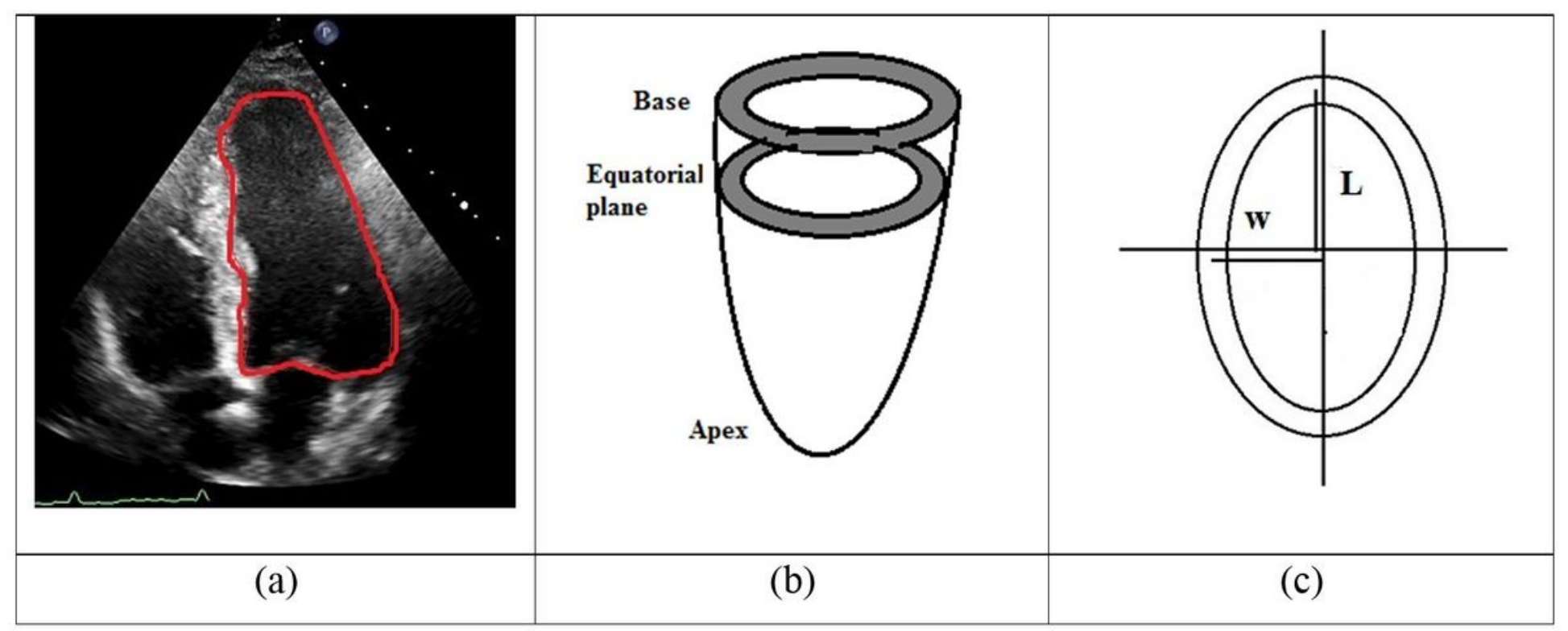

Figure 2

a) Four-chamber view used to determine the border of the LV, b) LV geometry, c) schematic view of the LV cavity in a long-axis plane for the ellipsoidal thick-walled theory on the equatorial plane.

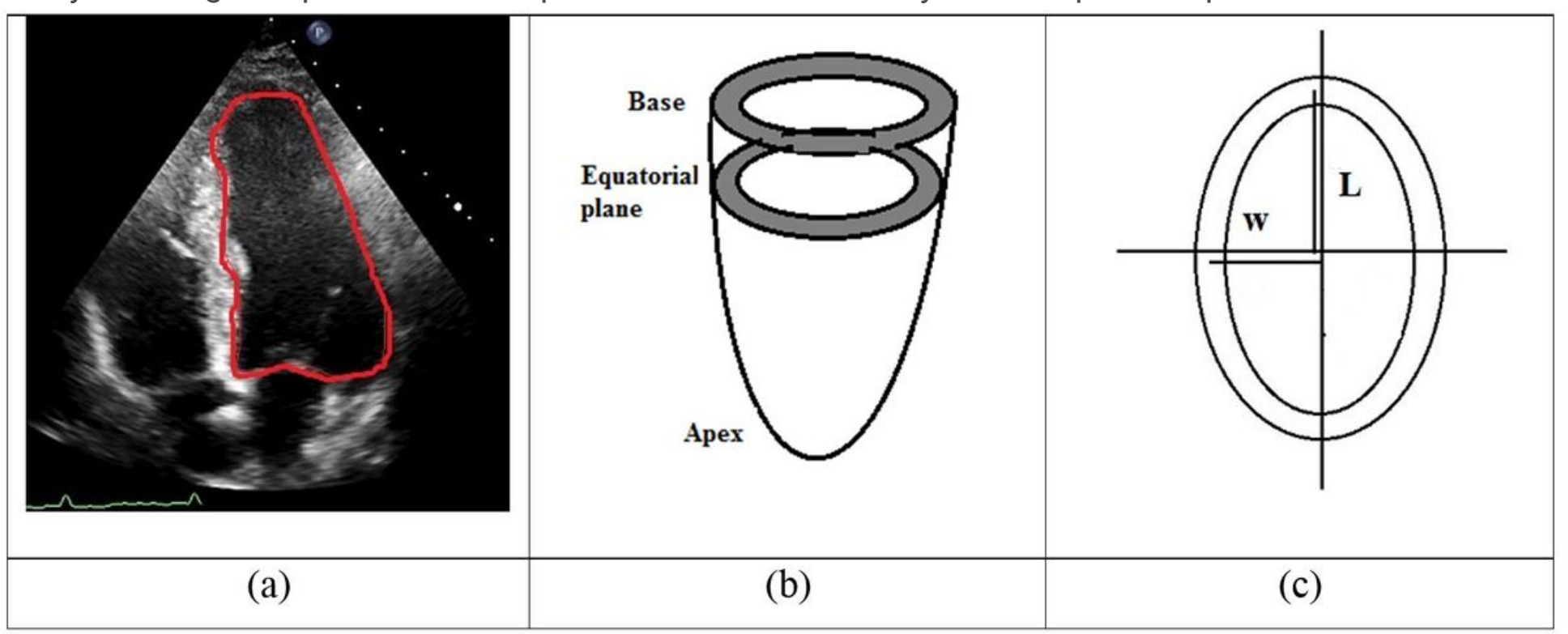

Figure 2

a) Four-chamber view used to determine the border of the LV, b) LV geometry, c) schematic view of the LV cavity in a long-axis plane for the ellipsoidal thick-walled theory on the equatorial plane. 


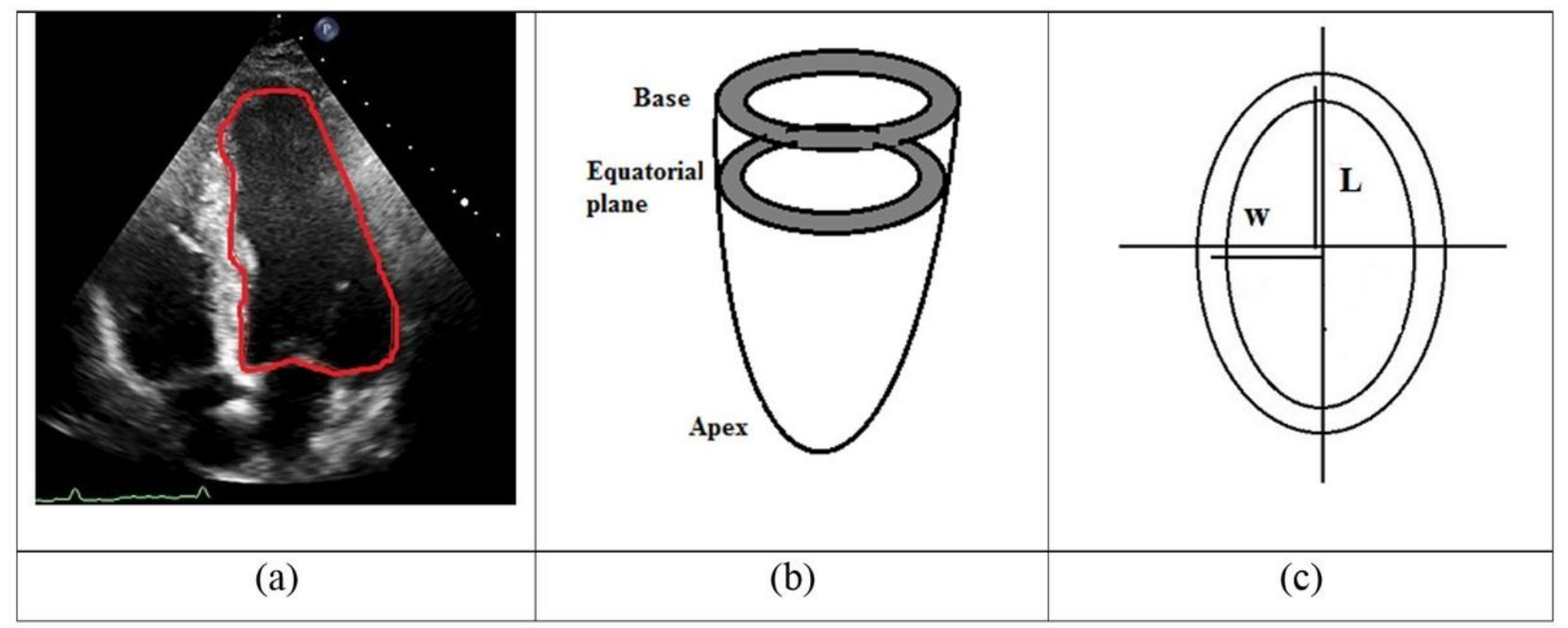

Figure 2

a) Four-chamber view used to determine the border of the LV, b) LV geometry, c) schematic view of the LV cavity in a long-axis plane for the ellipsoidal thick-walled theory on the equatorial plane.

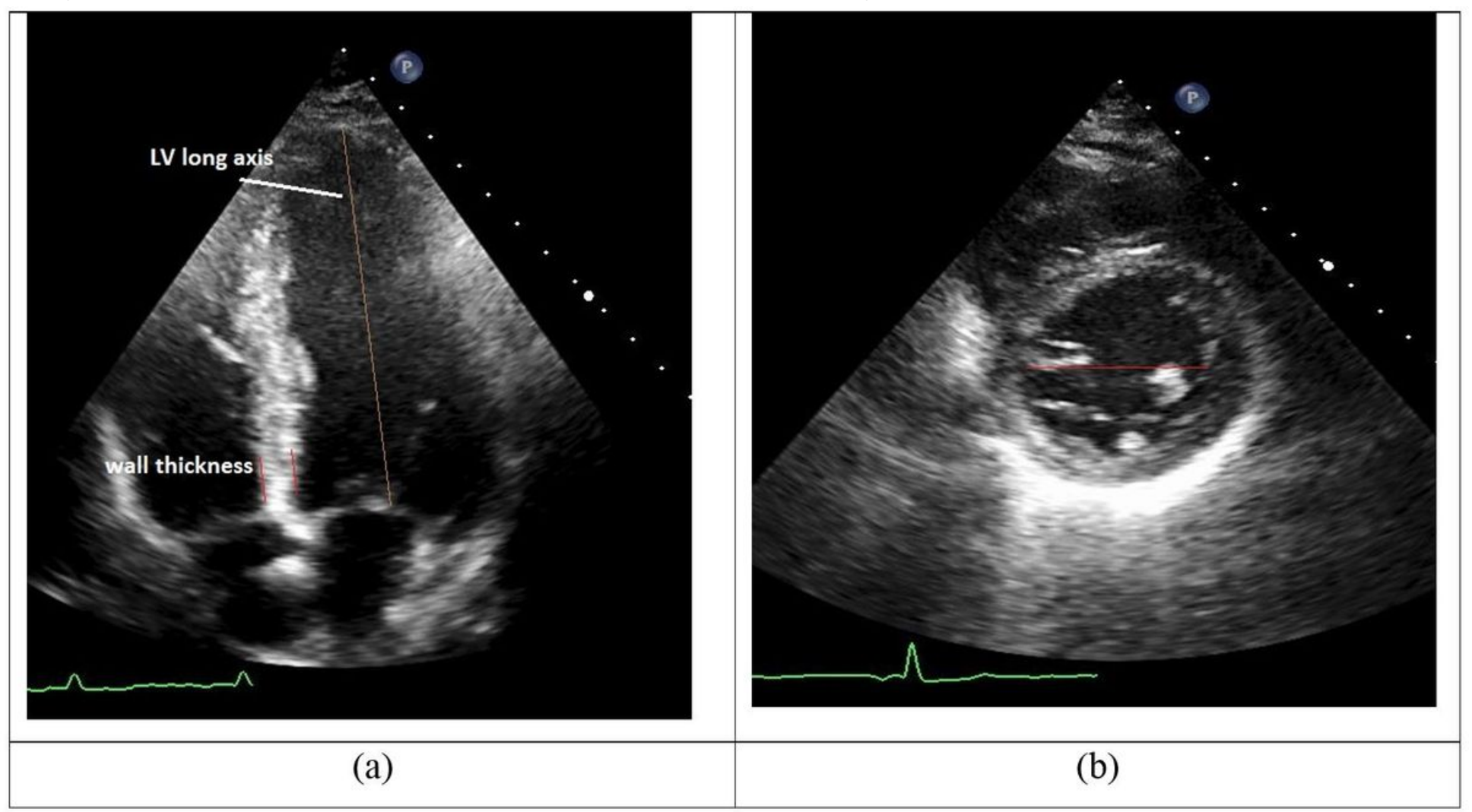

Figure 3

a) Four-chamber view used to determine the long axis and thickness of LV, b) short-axis view for the measurement of transverse diameter. 


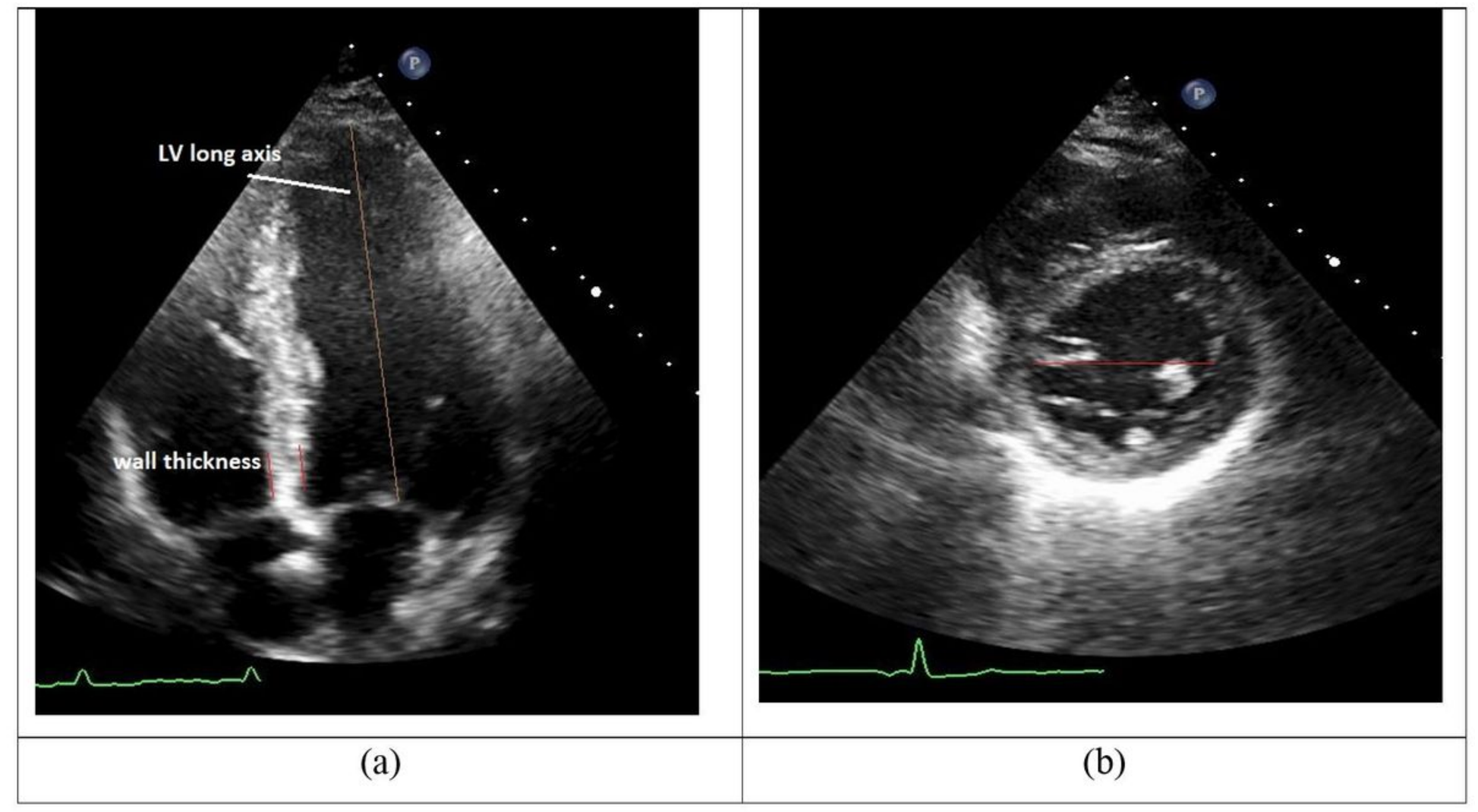

Figure 3

a) Four-chamber view used to determine the long axis and thickness of LV, b) short-axis view for the measurement of transverse diameter.

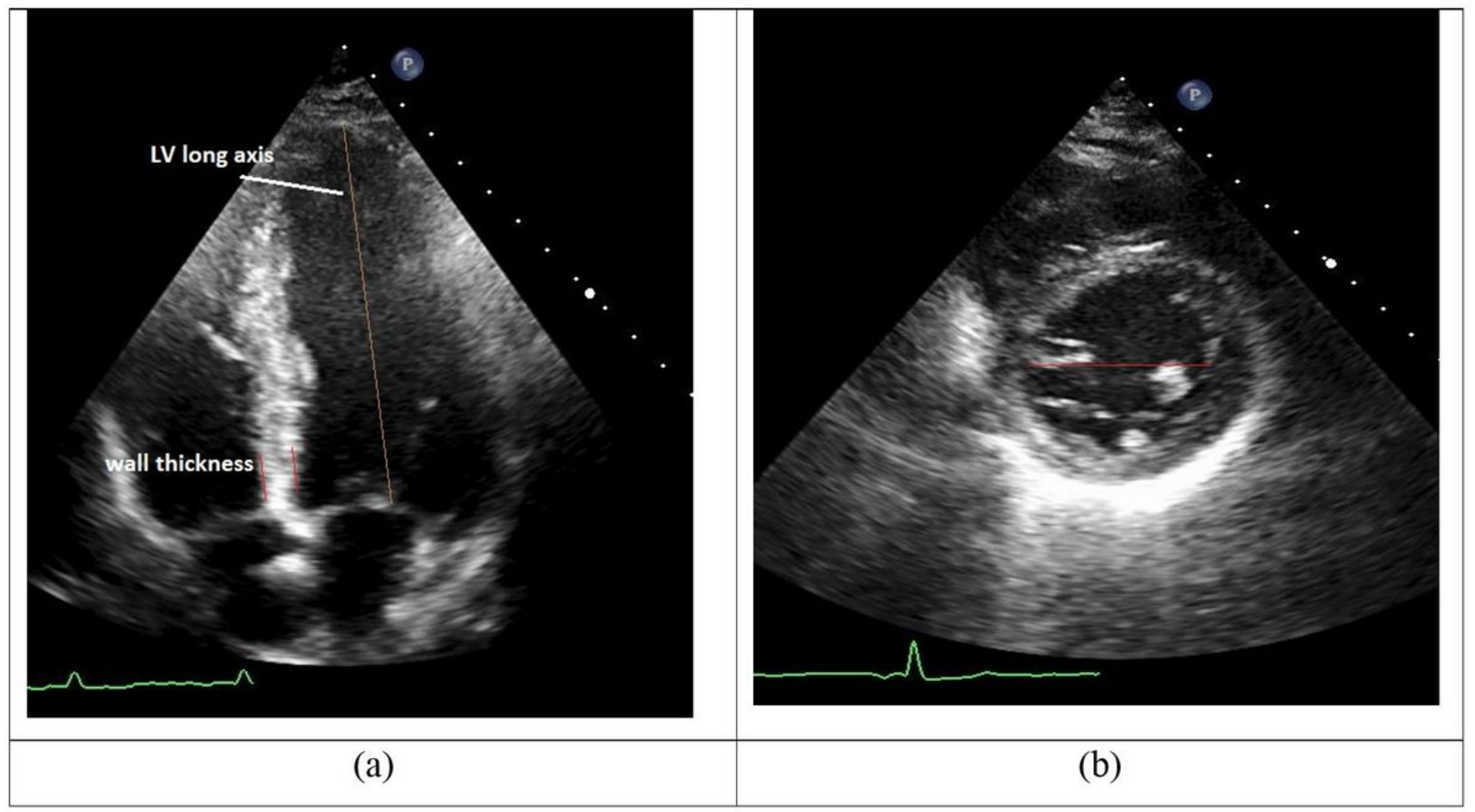


Figure 3

a) Four-chamber view used to determine the long axis and thickness of LV, b) short-axis view for the measurement of transverse diameter.

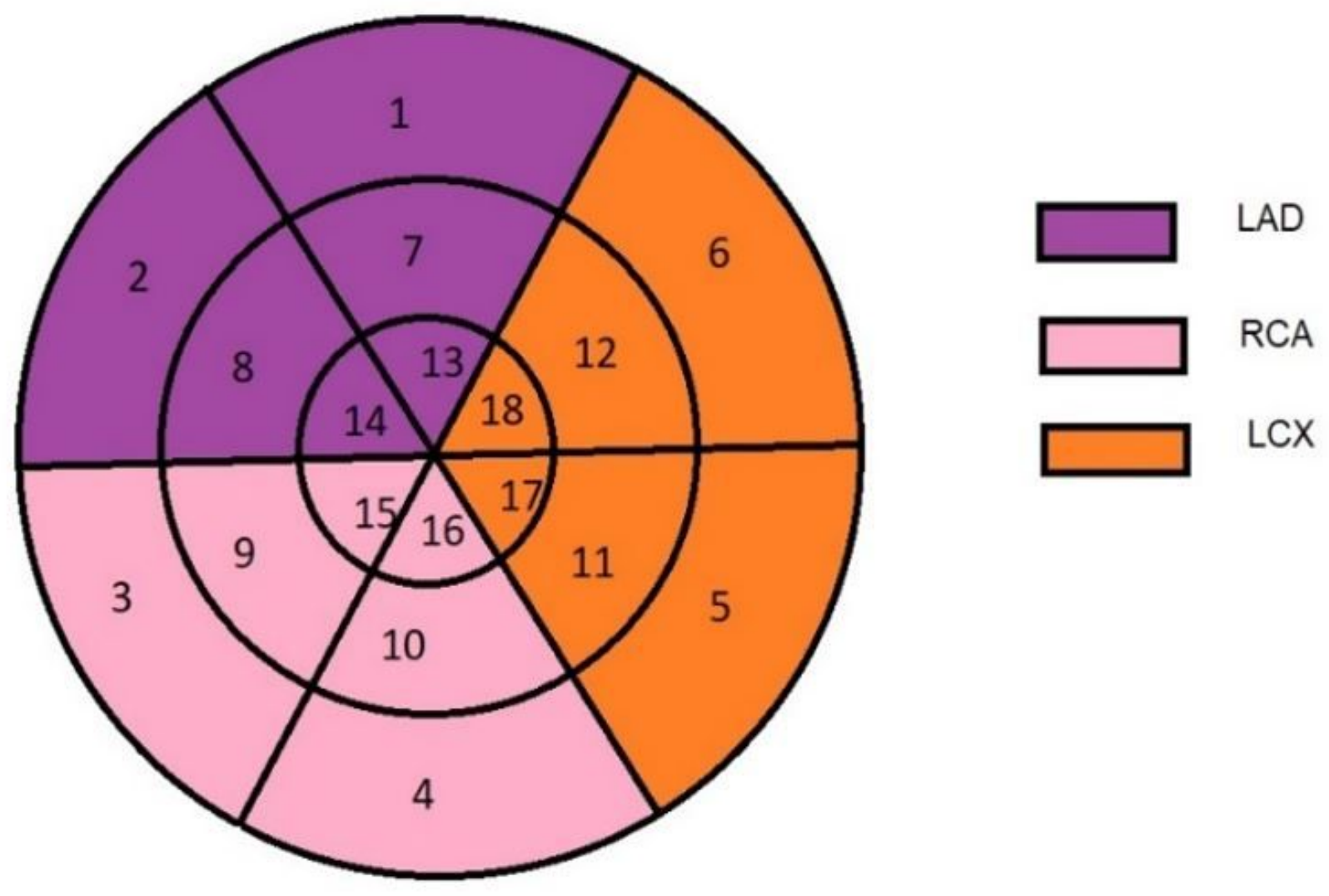

Figure 4

The 18-segment LV model shows that segments are subtended by coronary arteries (LAD, LCX, and RCA). LAD, RCA, and LCX supply purple, pink and orange segments, respectively (American Heart Association). 


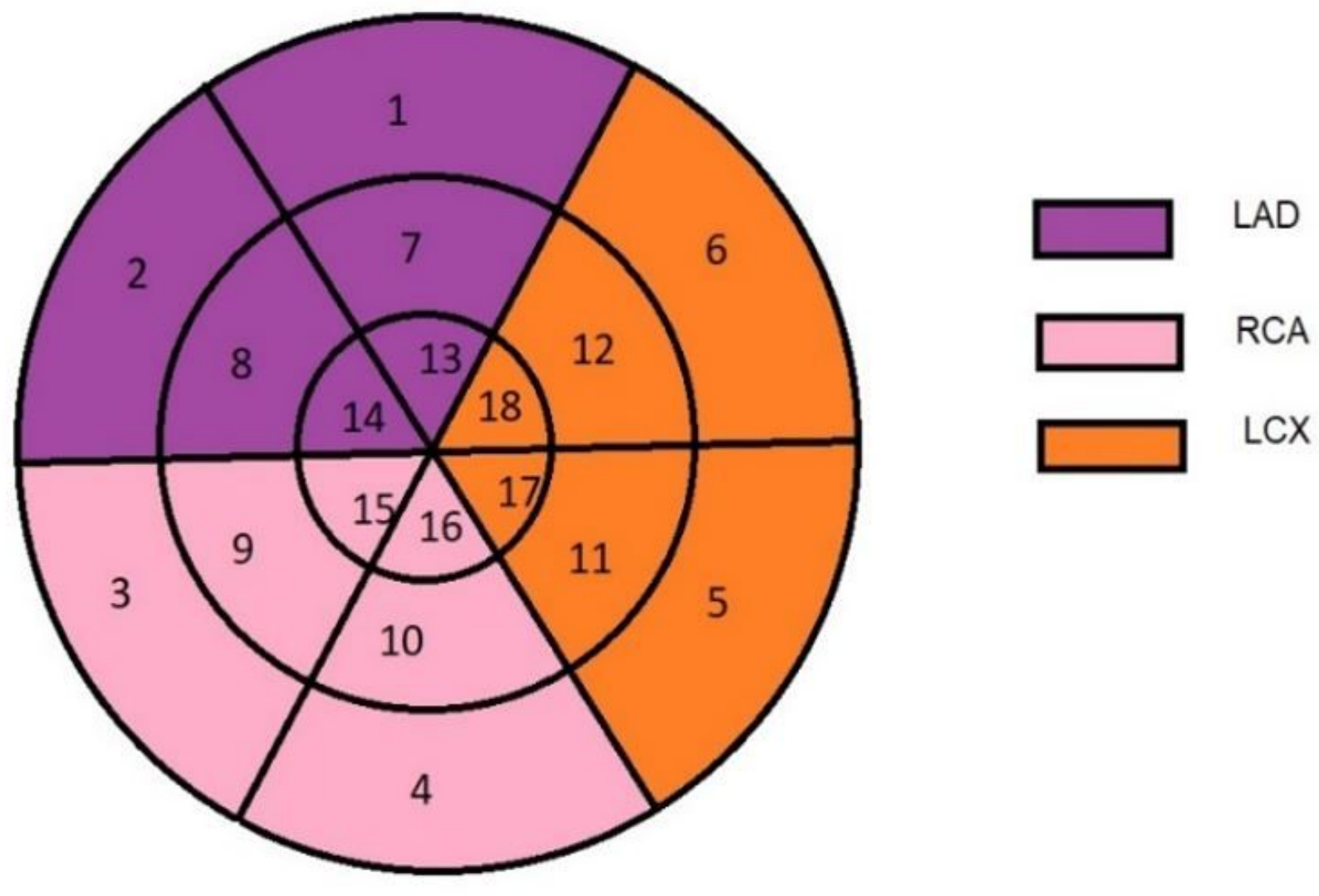

Figure 4

The 18-segment LV model shows that segments are subtended by coronary arteries (LAD, LCX, and RCA). LAD, RCA, and LCX supply purple, pink and orange segments, respectively (American Heart Association). 


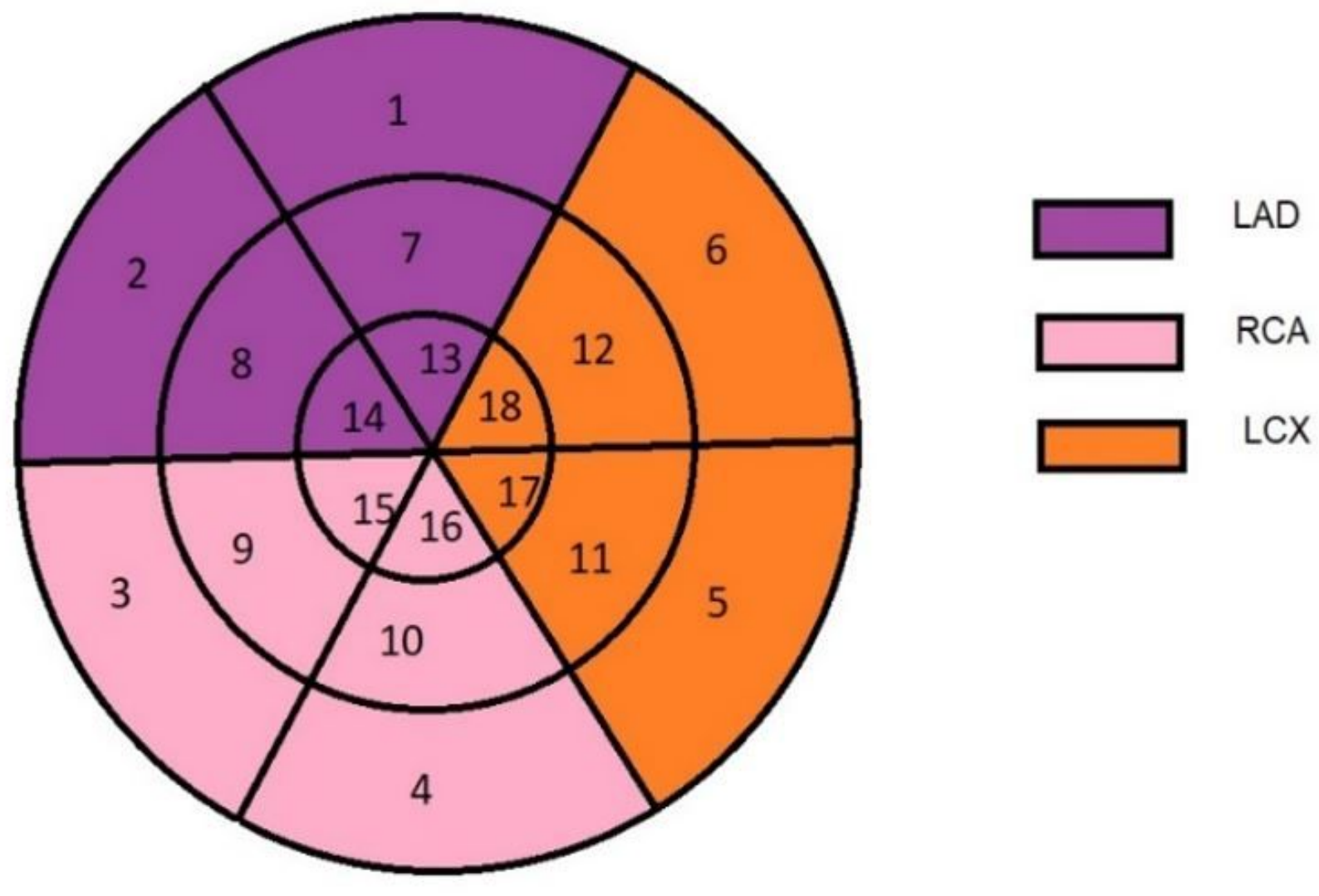

Figure 4

The 18-segment LV model shows that segments are subtended by coronary arteries (LAD, LCX, and RCA). LAD, RCA, and LCX supply purple, pink and orange segments, respectively (American Heart Association). 


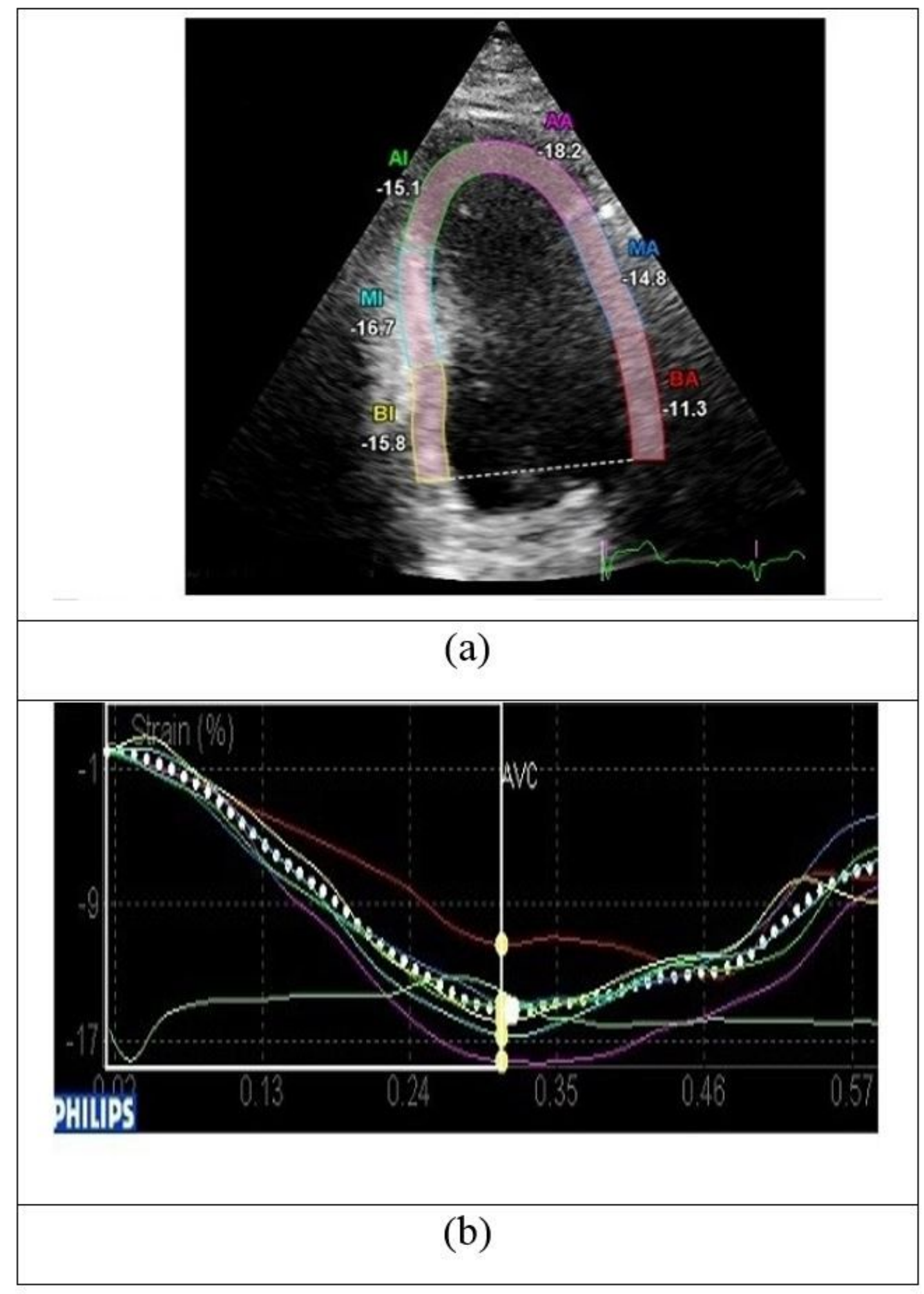

Figure 5

Longitudinal strain in the apical two-chamber view for a patient with coronary artery stenosis. a) Colorcoded strain images, and b) the related strain curves for six segments. 


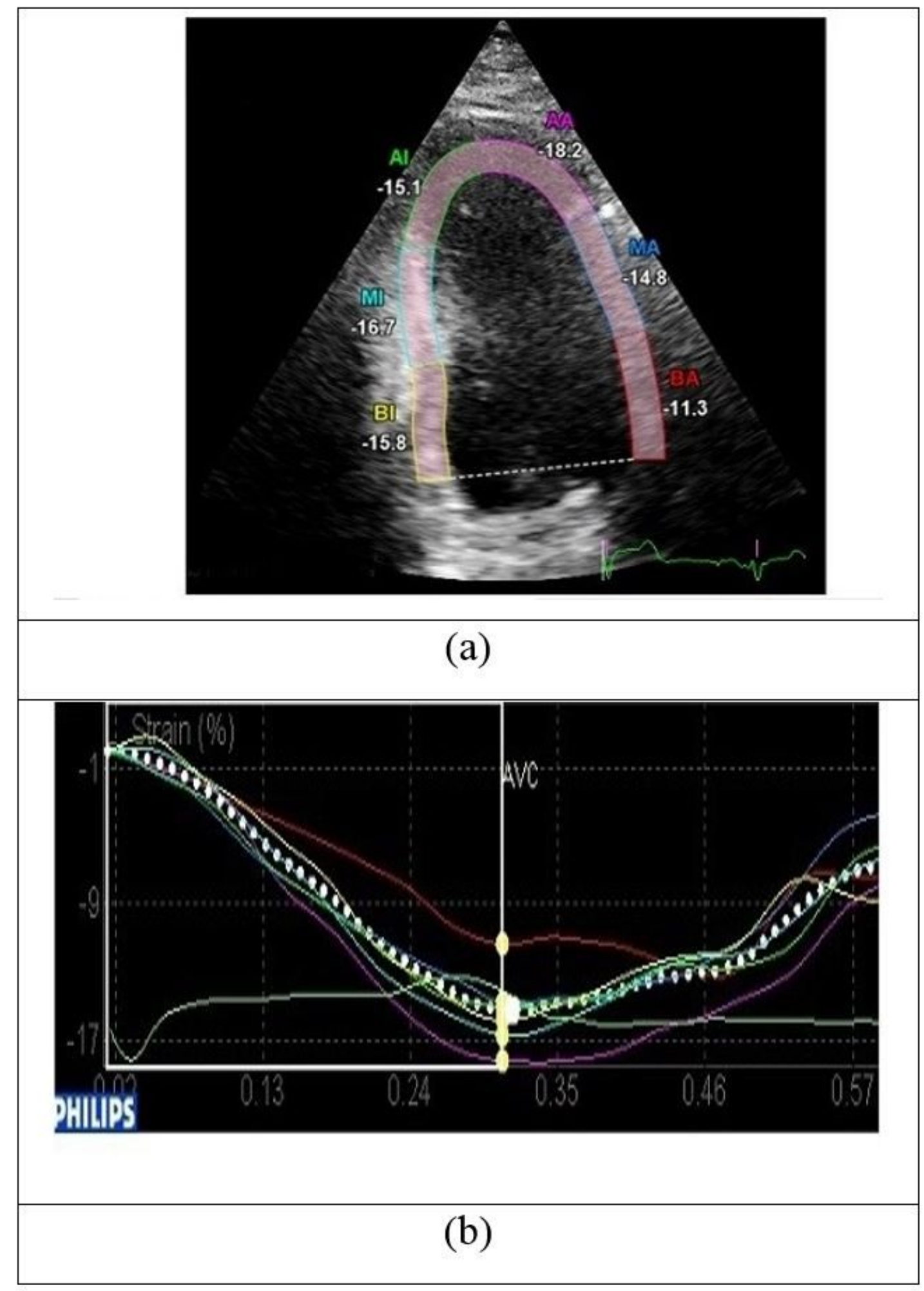

Figure 5

Longitudinal strain in the apical two-chamber view for a patient with coronary artery stenosis. a) Colorcoded strain images, and b) the related strain curves for six segments. 


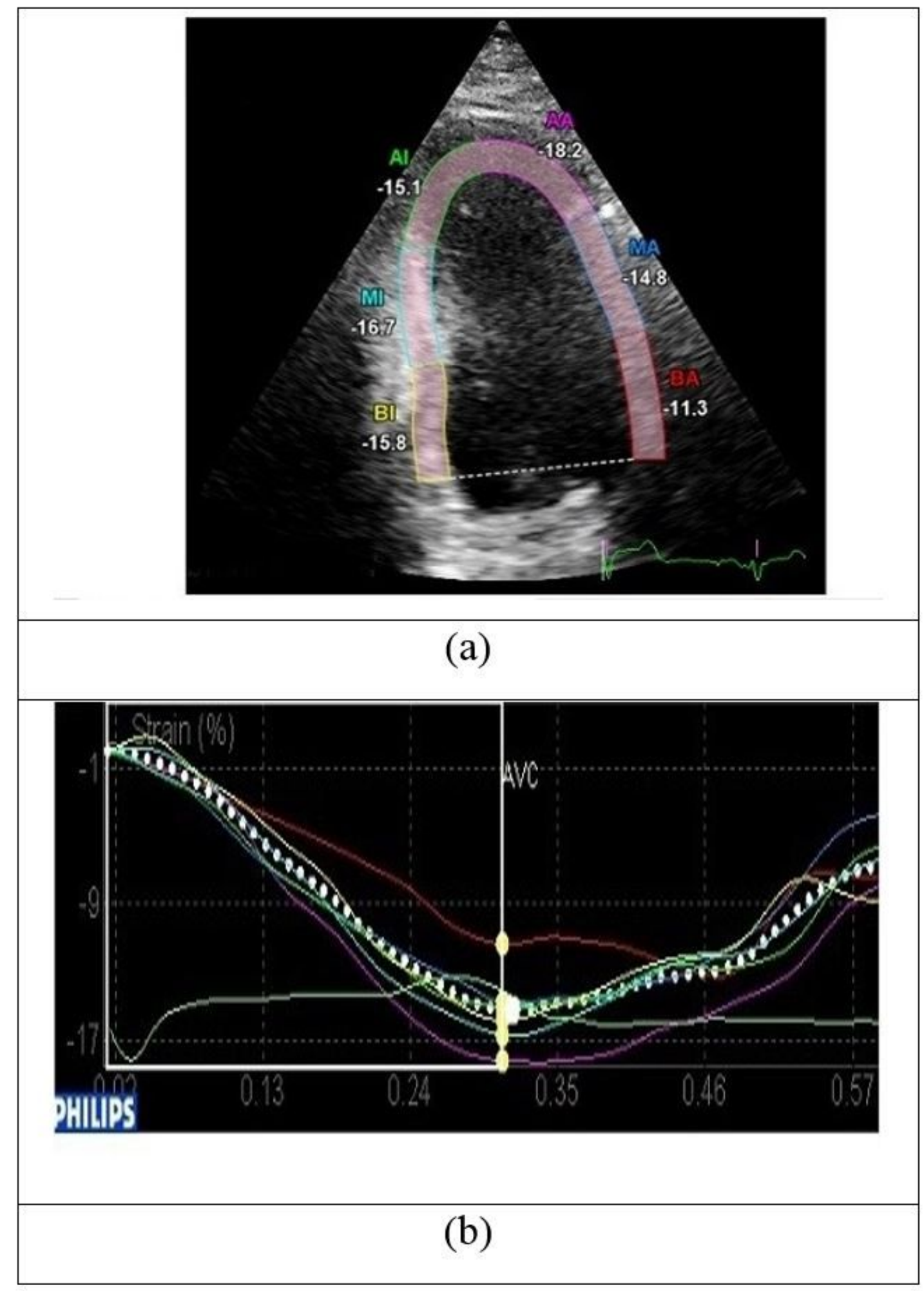

Figure 5

Longitudinal strain in the apical two-chamber view for a patient with coronary artery stenosis. a) Colorcoded strain images, and b) the related strain curves for six segments. 


(a)

Figure 6

ROC curve for the prediction of PCl patients for different variables, a) ROC curve for inferoseptal circumferential stress, b) ROC curve for anterior and inferoseptal strain, c) ROC curve for anterior and inferoseptal circumferential and longitudinal elastic modulus. 


(a)

Figure 6

ROC curve for the prediction of PCl patients for different variables, a) ROC curve for inferoseptal circumferential stress, b) ROC curve for anterior and inferoseptal strain, c) ROC curve for anterior and inferoseptal circumferential and longitudinal elastic modulus. 


(a)

Figure 6

ROC curve for the prediction of PCl patients for different variables, a) ROC curve for inferoseptal circumferential stress, b) ROC curve for anterior and inferoseptal strain, c) ROC curve for anterior and inferoseptal circumferential and longitudinal elastic modulus. 